\title{
Selective Attention to Specific Features within Objects: Behavioral and Electrophysiological Evidence
}

\author{
Anna Christina Nobre ${ }^{1}$, Anling Rao ${ }^{1}$, and Leonardo Chelazzi ${ }^{2}$
}

\begin{abstract}
Evidence regarding the ability of attention to bias neural processing at the level of single features has been gathering steadily, but most of the experiments to date used arrays with multiple objects and locations, making it difficult to rule out indirect influences from object or spatial attention. To investigate feature-specific selective attention, we have assessed the ability to select and ignore individual features within the same object. We used a negative-priming paradigm in which the color or the direction of internal motion of the object could determine the relevant response. Bidimensional (colored and moving) and unidimensional (colored and stationary, or gray and moving) stimuli appeared in unpredictable order. In successive blocks, participants were instructed that one feature dimension was dominant. During that block, participants responded according to the dominant dimension for bidimensional stimuli. For unidimensional stimuli, participants responded to the only dimension of the stimulus that afforded a response, regardless of the instruction for the block. The ability to inhibit irrelevant task information at the level of
\end{abstract}

\section{INTRODUCTION}

Selective attention is the cognitive function that builds awareness and optimizes purposeful action from the limitless possibilities afforded by the environment. It is becoming increasingly clear that attention is highly flexible, able to operate upon several types of representations and to modulate different levels of processing depending on the greatest points of information conflict or load (Nobre, 2004). So far, it has been established that we are able to select relevant objects (Duncan, 1984; Kahneman \& Treisman, 1984), spatial locations (Posner, 1980), instants of time (Griffin, Miniussi, \& Nobre, 2001; Coull \& Nobre, 1998), and motor responses (Rushworth, Nixon, Renowden, Wade, \& Passingham, 1997; Boussaoud \& Wise, 1993). Object and spatial attention in the visual modality have been the most extensively investigated. Their neural organization and mechanisms begin to be characterized. In both cases, especially under high perceptual load conditions (Lavie, 1995), attentional modulation starts at the perceptual

${ }^{1}$ University of Oxford, ${ }^{2}$ University of Verona specific features (negative priming for features) was indexed by a decrease in performance to detect one particular feature value (e.g., red) if the same feature value (red) but not another color value (green) had been ignored in the previous bidimensional stimulus. Behavioral results confirmed the existence of inhibitory, negative-priming mechanisms at the singlefeature level for both color and motion dimensions of stimuli. Event-related potentials recorded during task performance revealed the dynamics of neural modulation by feature attention. Comparisons were made using the identical physical stimuli under different conditions of attention to isolate purely attentional effects. Processing of identical bidimensional stimuli was compared as a function of the dimension of attention (color, motion). Processing of identical unidimensional stimuli that followed bidimensional stimuli was also compared to identify possible effects of feature-specific negative priming. The electrophysiological effects revealed that inhibition of irrelevant features leads to modulation of brain activity during early stages of perceptual analysis.

level in extrastriate visual areas (Valdes Sosa, Bobes, Rodriguez, \& Pinilla, 1998; Connor, Preddie, Gallant, \& Van Essen, 1997; Luck, Chelazzi, Hillyard, \& Desimone, 1997; Treue \& Maunsell, 1996; Heinze et al., 1994; Moran \& Desimone, 1985) and sometimes even in primary visual cortex (Roelfsema, Lamme, \& Spekreijse, 1998; Motter, 1993). Processing of target objects or locations is enhanced at the expense of inhibition of competing distractor information (Reynolds, Chelazzi, \& Desimone, 1999; Chelazzi, Duncan, Miller, \& Desimone, 1998; Treue \& Maunsell, 1996; Chelazzi, Miller, Duncan, \& Desimone, 1993 , 2001). The selection process is guided by parietalfrontal networks through top-down biasing signals (Nobre, 2001; Kastner \& Ungerleider, 2000; Desimone \& Duncan, 1995).

Less clearly established is the ability to select specific feature dimensions (e.g., color, direction of motion) or specific feature values (e.g., red, upward) independently of the selection of objects or locations. At first, features may not seem a natural unit for selection. After all, humans interact with objects and not isolated features. However, constituent features of objects may provide different amounts of information to guide action. In 
some cases, they may provide antagonistic information. For example, only a small variation in the color patterns will differentiate the killer coral snake from the innocuous scarlet king snake. It is important, therefore, to pay more attention to some constituent features than to others when deciding how to act toward an item in the world. Experimental tasks that capture this competition of features within objects are the Stroop task (Stroop, 1935) and the Wisconsin Card Sorting Task (Milner, 1963). In principle, feature selection should not be difficult to achieve in the brain. Much of the initial perceptual analysis of feature dimensions proceeds in parallel in specialized brain areas (Zeki, 1993; Felleman \& Van Essen, 1991; DeYoe \& Van Essen, 1988), and thus there would be a natural neural substrate for the selection of feature dimensions and values.

Some prominent theories of attention dispute the ability to select individual features within objects. They hold that once an object is selected, all of the constituent features are equally available, regardless of their relevance to the task at hand (Duncan, Humphreys, \& Ward, 1997; Duncan, 1984; Kahneman \& Treisman, 1984). Automatic coselection of constituent object features has been shown by use of both psychophysics (Rodriguez, Valdes Sosa, \& Freiwald, 2002; Blaser, Pylyshyn, \& Holcombe, 2000) and brain imaging (O'Craven, Downing, \& Kanwisher, 1999), although in these experiments there was no strong conflict between the constituent features of individual objects. The difficulty to select individual features of the same object has also been illustrated by the strong interference effects in Stroop tasks (Kahneman \& Henik, 1981; Stroop, 1935).

Nevertheless, strong hints of the existence of attentional modulation specific to feature dimensions and feature values are accumulating. When individuals have to match Stroop stimuli along only one dimension, interference from the competing dimension disappears (Treisman \& Fearnley, 1969), suggesting that it is possible to bias processing of such stimuli in favor of only one dimension. Using a flanker interference task (Eriksen \& Eriksen, 1974), Cohen and Shoup (1997) showed that only distractors with incongruent response assignments based upon the same feature dimension as the target cause interference. Incongruent flankers with response assignments based on other dimensions cause no interference (Remington \& Folk, 2001; Maruff, Danckert, Camplin, \& Currie, 1999). Kanwisher, Driver, and Machado (1995) showed that repetition blindness only occurs when a feature value of the relevant dimension is presented in two objects. Repetitions in the irrelevant feature dimension do not affect performance (see also Baylis \& Driver, 1993). Rossi and Paradiso (1995) showed that when participants discriminate the spatial frequency or orientation of a central grating stimulus, detection of a surrounding near-threshold annular grating is facilitated when its spatial frequency or orientation matches the relevant feature of the central stimulus.
Other forms of feature-based attention have been described in recent years at the behavioral level, including the differential weighting of feature dimensions in popout search tasks (Krummenacher, Mueller, \& Heller, 2001; Mueller, Heller, \& Ziegler, 1995) and the simultaneous enhancement of multiple objects across the visual field matching a given feature value, for example, of all red objects when red is the currently relevant feature value (Saenz, Buracas, \& Boynton, 2003).

Not much is known about the neural mechanisms for feature selection, although some pieces of the puzzle are emerging. Brain imaging has shown enhancement of brain activity in visual areas specialized for specific feature processing when the feature dimension directs attention toward object arrays (Serences, Schwarzbach, Courtney, Golay, \& Yantis, 2004; Giesbrecht, Woldorff, Song, \& Mangun, 2003; Liu, Slotnick, Serences, \& Yantis, 2003; Saenz, Buracas, \& Boynton, 2002; Buechel et al., 1998; O'Craven, Rosen, Kwong, Treisman, \& Savoy, 1997; Corbetta, Miezin, Shulman, \& Petersen, 1991). Feature-specific enhancement of activity in visual areas can occur even in the absence of visual stimulation, while the participants anticipate specific feature values (Chawla, Rees, \& Friston, 1999). Experiments using event-related potentials (ERPs) have typically shown that when relevant stimuli are defined by other features in addition to location, modulation of feature processing starts during perceptual analysis, but after modulation by spatial attention (Eimer, 1997; Anllo Vento \& Hillyard, 1996; Hillyard \& Munte, 1984), but in some cases, modulation of feature information precedes that of location information (Hopf, Boelmans, Schoenfeld, Luck, \& Heinze, 2004). Dipole-localization studies have placed the source of these modulations in visual areas specialized for the relevant feature processing (Anllo Vento, Luck, \& Hillyard, 1998). Some effects of attention to individual stimulus features have also been revealed with single-unit recording experiments in the behaving macaque (McClurkin \& Optican, 1996; Motter, 1994; Maunsell \& Hochstein, 1991; Haenny, Maunsell, \& Schiller, 1988; Haenny \& Schiller, 1988). However, very different forms of feature-specific attention were explored in these studies. In one case (Haenny et al., 1988; Haenny \& Schiller, 1988), it was the specific feature value held in short-term memory that was shown to modulate responses of neurons in V1 and V4 to a test grating stimulus presented within the context of a matching task. Otherwise, a specific feature value can be used to guide preselection of multiple, spatially dispersed potential targets possessing the matching feature value at the level of V4 (Motter, 1994). In still other cases, researchers have assessed the ability of attention to modulate processing of one or the other of the two constituent features of the same visual object in extrastriate cortex (McClurkin \& Optican, 1996; Maunsell \& Hochstein, 1991), but the results from the latter studies were rather ambiguous. Finally, it has been shown that 
selection of a moving object by its spatial location can lead to the enhanced representation of shared motion values in other, irrelevant objects (Martinez Trujillo \& Treue, 2004; Treue \& Martinez Trujillo, 1999), indicating that individual feature values can provide a substrate for modulation.

Although the accruing evidence is suggestive, most of the experiments to date use arrays with multiple objects and locations, making it difficult to rule out indirect influences from object or spatial attention. A more direct approach is to investigate feature selection within individual objects where the competing features overlap completely in spatial extent. We have recently provided evidence for feature selection in such a situation (Fanini, Nobre, \& Chelazzi, in press), using an adaptation of the negative-priming paradigm (Tipper, 1985). Constituent features of the same objects were shown to undergo different processing fates: Whereas the relevant target feature was made available to the response selection stage, the competing irrelevant features with incongruent response assignments were actively blocked.
The purpose of the present experiment was to investigate further the existence of feature selection independent of object or spatial attention and to reveal how it modulates the neural processing of stimuli. The task placed feature dimensions of simple stimuli presented at the center of gaze in direct competition (Figure 1). Values of color (red, green) and direction of motion (upward, downward) had incompatible response assignments, and therefore competed for controlling behavior. No spatial or object cues were available to guide selection. In successive short blocks, participants were instructed as to which dimension was relevant. Stimuli were either bidimensional (colored and moving) or unidimensional (colored and stationary, or gray and moving). For bidimensional stimuli, participants responded to the relevant dimension of the stimulus, depending on the instruction for the block. For unidimensional stimuli, participants responded to the only dimension of the stimulus that afforded a response, regardless of the instruction for the block. ERPs recorded during task performance revealed the dynamics
Figure 1. Schematic of the behavioral task. (Top) shows a sample task sequence, with block instructions followed by bidimensional and unidimensional stimuli (after 250-600 msec interval) Bidimensional stimuli were colored (red or green) and contained internal motion (upward or downward). Unidimensional stimuli were colored (red or green) and stationary, or gray and moving (upward or downward). Stimuli appeared foveally (150 msec duration), $100 \mathrm{msec}$ after the response time to the preceding stimulus. For bidimensional stimuli, participants responded according to the feature in the dominant dimension, whereas for unidimensional stimuli, they responded according to the only relevant feature. The correct response is indicated in the lower right of each trial panel. Only stimuli following bidimensional stimuli were analyzed. (Bottom) Shows the different possible types of relationships between a unidimensional probe and the preceding bidimensional stimulus. When the feature dimension was dominant in the block $\left(\mathrm{D}^{+}\right)$, the specific

feature value could be repeated $\left(\mathrm{D}^{+} \mathrm{F}^{+}\right)$or nonrepeated $\left(\mathrm{D}^{+} \mathrm{F}^{-}\right)$. The comparison between $\mathrm{D}^{+} \mathrm{F}^{+}$and $\mathrm{D}^{+} \mathrm{F}^{-}$provides a measure of feature-specific positive priming. When the feature dimension was ignored in the block $\left(\mathrm{D}^{-}\right)$, the specific feature value could be repeated $\left(\mathrm{D}^{-} \mathrm{F}^{+}\right.$) or nonrepeated $\left(\mathrm{D}^{-} \mathrm{F}^{-}\right)$. The comparison between $\mathrm{D}^{-} \mathrm{F}^{+}$and $\mathrm{D}^{-} \mathrm{F}^{-}$provides a measure of negative priming.

\section{Sample task sequence}

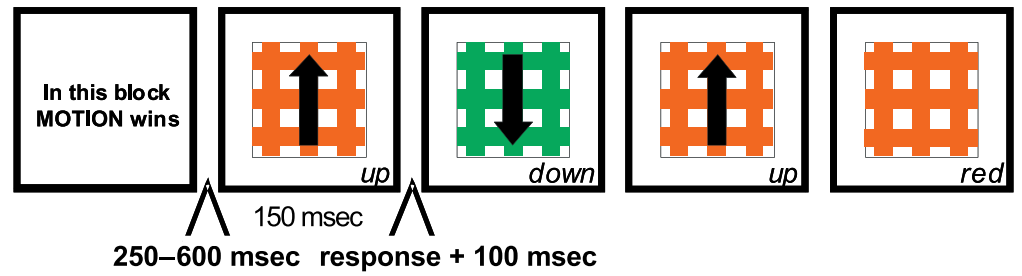

Prime-Probe relationships

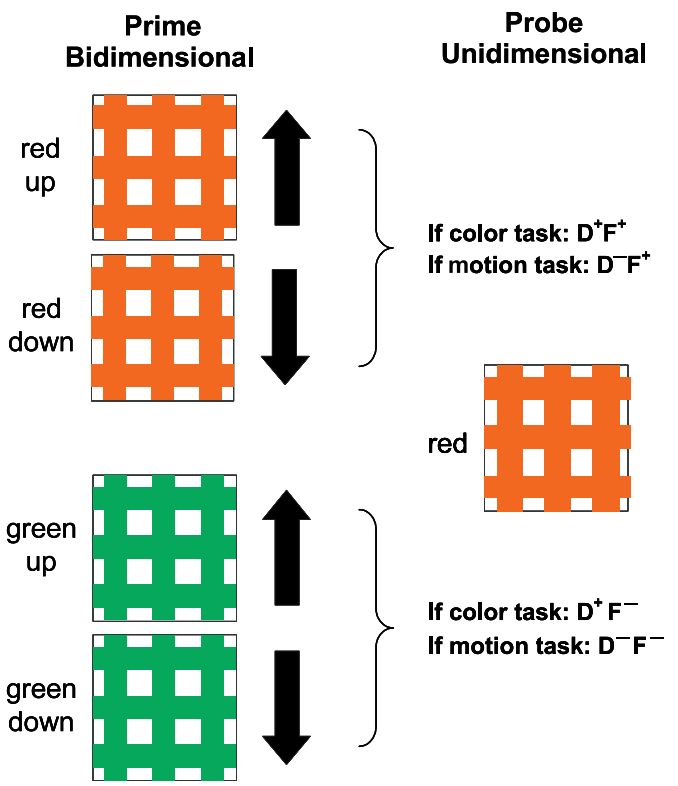


of neural modulation by feature attention. Comparisons were made using the identical physical stimuli under different conditions of attention in order to isolate purely attentional effects. Processing of identical bidimensional stimuli was compared as a function of the dimension of attention (color, motion). Processing of identical unidimensional stimuli that followed bidimensional stimuli was also compared to identify possible effects of feature-specific negative priming (Tipper, 1985). Feature-specific negative priming was indexed as a decrease in performance to detect one particular feature value (e.g., red) if the same feature value (red) but not another color value (green) had been ignored in the previous bidimensional stimulus.

In addition to revealing reliable behavioral and neural measures of feature-specific attention, the results of the experiment may also have implications for theories of negative priming. Specifically, the collected evidence allows us to determine to what extent negative priming effects, at least under our testing conditions, reflect lingering suppressive influences on the perceptual representation of ignored features, or instead support modulations at later stages of processing implicated in memory retrieval and response selection (Tipper, 2001). Finally, the experimental design gives us the opportunity to explore the neuronal underpinnings of task-switching costs, that is, the costs ensuing from the need to reconfigure task-set in the condition where different tasks are to be performed in two consecutive trials versus when the same task set is maintained across the trial sequence (Rushworth, Passingham, \& Nobre, 2002, 2005; Rogers \& Monsell, 1995; Allport, Styles, \& Hsieh, 1994).

\section{RESULTS}

\section{Behavioral Performance}

Accuracy to discriminate bidimensional stimuli was high overall and did not differ significantly for the color (92\%) versus motion (91\%) tasks or for the different stimulus types. Analysis of median reaction times (RTs) for bidimensional stimuli revealed only a main effect of dominant dimension, $F(1,14)=5.13, p=.04$. Participants were significantly faster to discriminate the color hue, in the color-wins task (399 msec), than the direction of motion, in the motion-wins task (418 msec). There was no significant difference in performance between the four stimulus types (red-up, red-down, green-up, greendown), and dominant dimension did not interact with either bue or direction of the stimulus.

Figure 2 summarizes the behavioral results for unidimensional stimuli. Analysis of the median RTs to unidimensional stimuli considered whether the single feature belonged to the dominant feature dimension $\left(\mathrm{D}^{+}\right)$or not $\left(\mathrm{D}^{-}\right)$, whether the single feature was repeated from the previous bidimensional stimulus $\left(\mathrm{F}^{+}\right)$or not $\left(\mathrm{F}^{-}\right)$, and the specific direction (up vs. down) or hue (red vs. green) of the motion or color feature, respectively. The analysis showed attention effects at both the level of the dimension and of the individual feature value selected for both color and motion stimuli. The dimensionselection, or task-switching, effect $\left[\left(\mathrm{D}^{+} \mathrm{F}^{+} \& \mathrm{D}^{+} \mathrm{F}^{-}\right) \mathrm{vs}\right.$. $\left.\left(\mathrm{D}^{-} \mathrm{F}^{+} \& \mathrm{D}^{-} \mathrm{F}^{-}\right)\right]$was reflected in the highly significant main effect of dominant dimension for both types of stimuli: color: $F(1,14)=438.61, p<.0001$; motion: $F(1,14)=98.77, p<.0001$. Reaction times to unidimensional stimuli were much faster $(>100 \mathrm{msec})$ when that dimension was dominant in the task block, that is, when no task-switching operation was required. The attention effect at the level of the individual feature value depended on inhibition of the particular feature value in the preceding bidimensional stimulus. The attention effect was reflected in significant interactions between dominant dimension and feature repetition factors $\left[\left(\mathrm{D}^{+} \mathrm{F}^{+}\right.\right.$vs. $\left.\mathrm{D}^{+} \mathrm{F}^{-}\right)$vs. $\left(\mathrm{D}^{-} \mathrm{F}^{+}\right.$vs. $\left.\left.\mathrm{D}^{-} \mathrm{F}^{-}\right)\right]$for both color stimuli, $F(1,14)=8.56, p=.011$, and motion stimuli, $F(1,14)=14.88, p=.002$. For both color and motion stimuli, the dominant dimension by feature repetition interactions reflected mainly a negative-priming effect. For color stimuli, the interaction indicated that RTs were slowed when the identical hue was ignored (584 msec) compared to when the other hue was ignored (572 msec): $\left(\mathrm{D}^{-} \mathrm{F}^{+}\right.$vs. $\left.\mathrm{D}^{-} \mathrm{F}^{-}\right): t(14)=2.44, p=$ .03. Reaction times appeared to be facilitated when the identical hue was selected (376 msec) compared to when the other hue was selected $(385 \mathrm{msec})$, but this effect did not reach statistical significance, $\left(\mathrm{D}^{+} \mathrm{F}^{+}\right.$vs. $\left.\mathrm{D}^{+} \mathrm{F}^{-}\right): t(14)=1.49, p=.16$. There was no overall effect of feature repetition, $\left(\mathrm{D}^{+} \mathrm{F}^{+}\right.$vs. $\left.\mathrm{D}^{+} \mathrm{F}^{-}\right)$and $\left(\mathrm{D}^{-} \mathrm{F}^{+}\right.$vs. $\left.\mathrm{D}^{-} \mathrm{F}^{-}\right): F(1,14)=0.64, p=.47$, but there was an overall facilitation to detect red stimuli if red was repeated, as shown by the interaction between feature repetition and bue, $F(1,14)=8.95, p=.01$; red stimulus Same $\times$ Different: $t(14)=2.94, p=.01$. For motion stimuli, RTs were significantly slowed when the identical direction was ignored (573 $\mathrm{msec}$ ) compared to when the other direction was ignored (542 $\mathrm{msec})$ in the preceding display, $\left(\mathrm{D}^{-} \mathrm{F}^{+}\right.$vs. $\left.\mathrm{D}^{-} \mathrm{F}^{-}\right): t(14)=6.80, p=.001$. Reaction times were equivalent when the identical direction (419 $\mathrm{msec}$ ) or the other direction (418 $\mathrm{msec}$ ) was selected in the preceding display, $\left(\mathrm{D}^{+} \mathrm{F}^{+}\right.$vs. $\left.\mathrm{D}^{+} \mathrm{F}^{-}\right)$: $t(14)=0.11, p=.92$. A main effect of feature repetition was also obtained $\left[\left(\mathrm{D}^{+} \mathrm{F}^{+}\right.\right.$vs. $\left.\mathrm{D}^{+} \mathrm{F}^{-}\right)$and $\left(\mathrm{D}^{-} \mathrm{F}^{+}\right.$vs. $\left.\left.\mathrm{D}^{-} \mathrm{F}^{-}\right)\right]$, indicating that overall the reaction times to detect repeated directions were slower, $F(1,14)=$ $11.84, p=.004$. The specific hue or direction of unidimensional stimuli did not affect reaction times significantly, $F(1,14)<.1, p>.76$, and no further interactions were observed.

Accuracy to discriminate unidimensional stimuli was high overall for both color (90\%) and motion stimuli (90\%), and was significantly affected by the dominant dimension in both cases, $\left(\mathrm{D}^{+} \mathrm{F}^{+} \& \mathrm{D}^{+} \mathrm{F}^{-}\right)$vs. $\left(\mathrm{D}^{-} \mathrm{F}^{+}\right.$\& 


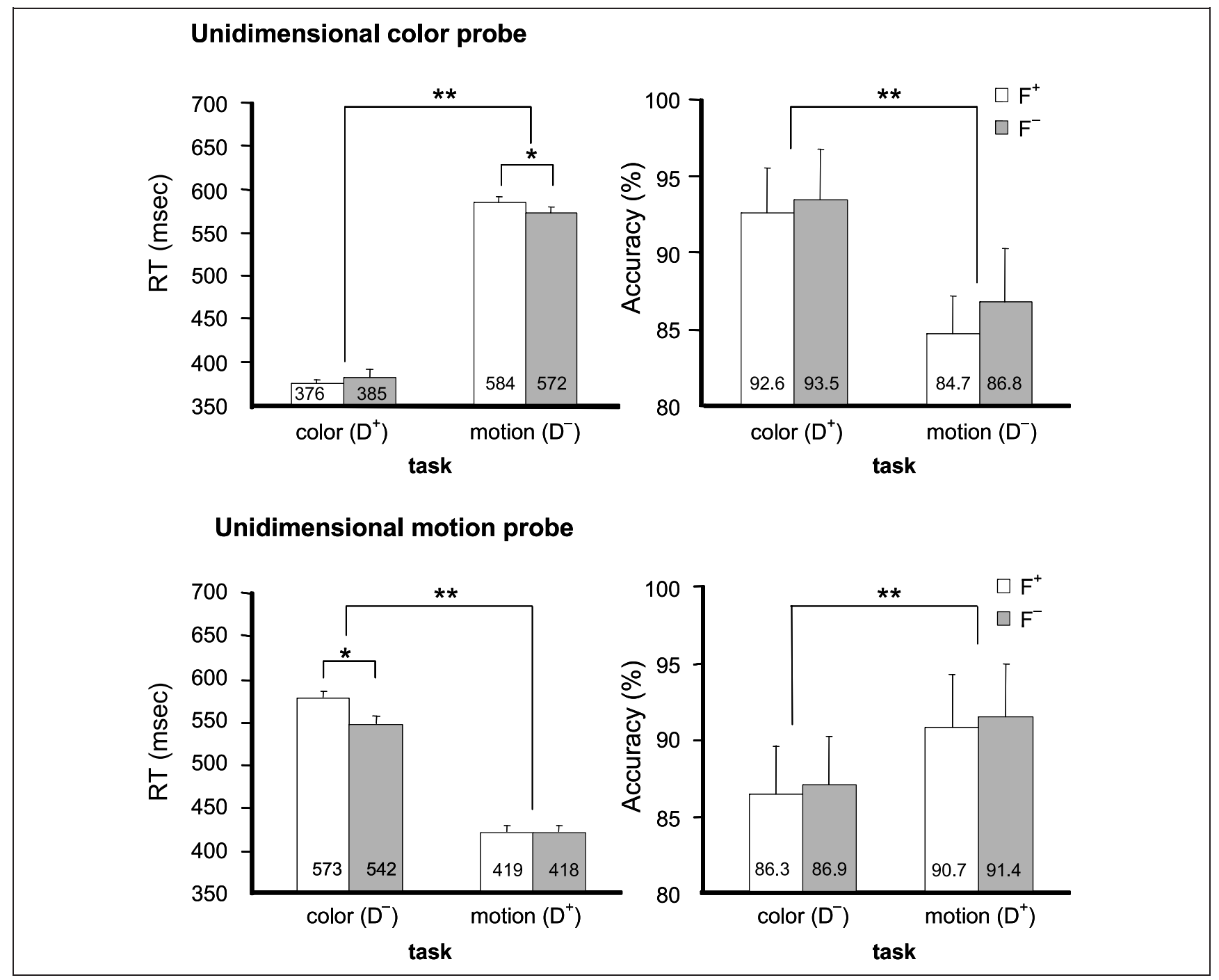

Figure 2. Behavioral results for unidimensional stimuli. The top graphs show mean of median RTs (left) and accuracy (right) for unidimensional color probes. Participants were faster and more accurate to respond to color hues in the color-dominant task. In addition, participants were slower to respond to a repeated versus nonrepeated color hue in the motion-dominant task (negative priming). The bottom graphs show mean of median RTs (left) and accuracy (right) for unidimensional motion probes, for which the same pattern of results was obtained. Participants were faster and more accurate to respond to motion directions in the motion-dominant task. In addition, participants were slower to respond to a repeated versus nonrepeated motion direction in the color-dominant task (negative priming).

$\left.\mathrm{D}^{-} \mathrm{F}^{-}\right)$: color stimuli: $F(1,14)=22.23, p<.001 ;$ motion stimuli: $F(1,14)=21.88, p<.001$. In both cases, participants discriminated the feature value more accurately when the stimulus dimension was the dominant one in the trial block, that is, when no task-switching operation was required. For color stimuli there was also a three-way interaction between dominant dimension in the block, feature repetition, and hue, $F(1,14)=$ 5.35, $p=.04$. Post hoc comparisons indicated that there was a significant negative-priming effect $\left(\mathrm{D}^{-} \mathrm{F}^{+}\right.$ vs. $\mathrm{D}^{-} \mathrm{F}^{-}$) for red, $t(14)=2.55, p=.02$, but not green stimuli, $t(14)=0.83, p=.42$, and no significant positive priming effects, $\left(\mathrm{D}^{+} \mathrm{F}^{+}\right.$vs. $\left.\mathrm{D}^{+} \mathrm{F}^{-}\right): t(14)<1.1$, $p>$.30. There was also an overall slight facilitation to discriminate a red stimulus if it was repeated across consecutive displays - an effect reflected in the marginal in- teraction between feature repetition and hue, $F(1,14)=$ 4.62, $p=.05$; red stimulus Same $\times$ Different: $t(14)=$ $2.34, p=.04$. For motion stimuli, there were no significant effects or interactions involving feature repetition or direction of motion.

\section{Event-related Potentials}

The main purpose of the ERP analysis was to investigate whether the processing of feature dimensions or individual feature values could be modulated selectively according to their behavioral relevance in the motiondominant versus color-dominant task conditions. Of particular interest was the putative modulation of perceptual stages of stimulus analysis by selective attention 
to feature dimensions or feature values in the absence of spatial or object-related information to guide selective attention.

\section{Selective Attention to Color or Motion of Bidimensional Stimuli}

The most pronounced components of the grand-averaged ERP waveforms elicited by bidimensional stimuli were visual potentials $\mathrm{P} 1$ and $\mathrm{N} 1$, followed by a late positive P300 component. The first discernible component was a lateral posterior positive component (P1) maximal at around 80 msec over occipital electrodes PO7 and PO8. Between 100 and $120 \mathrm{msec}$, the P1 acquired a midline posterior distribution, with maximum voltage at POZ. The N1 followed between 120 and 200 msec. The N1 was also distributed over lateral occipital electrodes PO7 and PO8, and peaked at around $140 \mathrm{msec}$. The negative occipital potential was accompanied by positive voltage over the frontal scalp. The latencies and distributions for these visual potentials were the same in the two task conditions. The P300 was focally and centrally distributed around the midline parietal electrode $\mathrm{Pz}$ and $\mathrm{POz}$. The peak of the P300 occurred earlier for the color-dominant condition (352 $\mathrm{msec}$ ) than the motion-dominant condition (372 msec).

Selective attention to either color or motion had significant effects upon the processing of bidimensional foveal objects, starting from early stages in perceptual analysis (Figure 3). Task-related modulations of the ERPs occurred during visual potentials in stimulus-specific ways. The mean amplitude of P1 was influenced by an interaction between dominant dimension, hue, and direction of motion, $F(1,14)=5.13, p=.04$. The modulations went in opposite directions for upward and downward moving gratings. When P1 modulation by the dominant-dimension condition was tested for each stimulus type separately, only the effect for green downward gratings approached significance, $t(14)=2.03$, $p=.06$. The $\mathrm{N} 1$ was influenced by an interaction between dominant dimension and direction of motion, $F(1,14)=6.76, p=.02$. The N1 was larger when motion was the attended dimension for the downward, $t(14)=2.17, p=.04$, but not upward, $t(14)=1.20$, $p=.24$, moving gratings.

Task condition did not alter the amplitude of the P300 significantly, but did have a significant effect on its latency, $F(1,14)=13.00, p=.003$. The $\mathrm{P} 300$ component peaked earlier in the color task than in the motion task. This pattern paralleled the shorter RTs in the color compared to motion task.

Regional analyses (see Methods for details) corroborated the results from the analyses of components. Two types of modulations related to the selection of color or motion values in bidimensional stimuli. The first effect occurred during visual analysis, between 60 and $160 \mathrm{msec}$, and was consistent with modulation of visual compo- nents noted above. The earliest effects appeared as threeway interactions between dominant dimension, hue, and direction of motion in the midline (60-120 msec) and central regions (80-120 msec), all Fs $(1,14)>5.1, p<$ .05 . There were also early effects that did not interact with motion or color values, appearing as main effects of dominant dimension at central (120-160 msec), lateral (120-160 msec), and frontal (120-160 msec) regions; and an interaction between dominant dimension and electrode at the midline region (80-160 msec), all $F_{\mathrm{S}}(1,14)>4.8, p<.05$. The waveforms elicited by bidimensional stimuli in the motion task were relatively more positive over posterior midline electrodes and relatively more negative over central, lateral, and frontal electrodes.

The second type of modulation reflected the earlier rise and fall of the P300 component elicited when color was the dominant dimension. During the rise time of the P300 (240-340 msec), ERP waveforms elicited in the color-selection task were more positive. A main effect of dominant dimension was observed at midline (240-340 msec), central (260-340 msec), lateral (240-340 $\mathrm{msec})$, and posterior (260-340 $\mathrm{msec})$ regions, all $F \mathrm{~S}(1,14)>5.0, p<.05$. After the peak of the P300, the waveforms elicited during the motionselection task were more positive (420-600 msec). A main effect of dominant dimension was observed at midline (420-520 msec) and posterior (460-520 msec) regions. More focal effects were reflected in interactions between dominant dimension, electrode, and/ or hemisphere over midline (420-600 msec), frontal (420-500 msec), and central (440-600 msec) regions, all $F \mathrm{~s}>3.2, p<.05$.

\section{Dimension- and Feature-selection Effects upon Unidimensional Stimuli}

The general shape of waveforms elicited by unidimensional motion and color stimuli was similar, and was similar to that elicited by bidimensional stimuli. The most prominent potentials were the P1 (lateral and midline), N1, and P300. The analysis of ERPs elicited by unidimensional stimuli revealed effects of selective attention operating at the level of individual features as well as at the more general level of feature dimension. Feature-specific selective attention effects were revealed by interactions involving dominant dimension and feature repetition factors $\left[\left(\mathrm{D}^{+} \mathrm{F}^{+}\right.\right.$vs. $\left.\mathrm{D}^{+} \mathrm{F}^{-}\right)$vs. $\left(\mathrm{D}^{-} \mathrm{F}^{+}\right.$vs. $\left.\left.\mathrm{D}^{-} \mathrm{F}^{-}\right)\right]$. Within this interaction, it was possible to dissociate separate effects of inhibiting the processing of an irrelevant feature on the preceding trial [feature-specific negative priming: $\left(\mathrm{D}^{-} \mathrm{F}^{+}\right.$vs. $\left.\mathrm{D}^{-} \mathrm{F}^{-}\right)$] from effects of selecting a relevant feature on the preceding trial [featurespecific positive priming: $\left(\mathrm{D}^{+} \mathrm{F}^{+}\right.$vs. $\left.\left.\mathrm{D}^{+} \mathrm{F}^{-}\right)\right]$. Selective attention effects operating at the level of the feature dimension were identified as a main effect of the dominant dimension in the task $\left[\left(\mathrm{D}^{+} \mathrm{F}^{+} \& \mathrm{D}^{+} \mathrm{F}^{-}\right)\right.$vs. $\left(\mathrm{D}^{-} \mathrm{F}^{+}\right.$ 


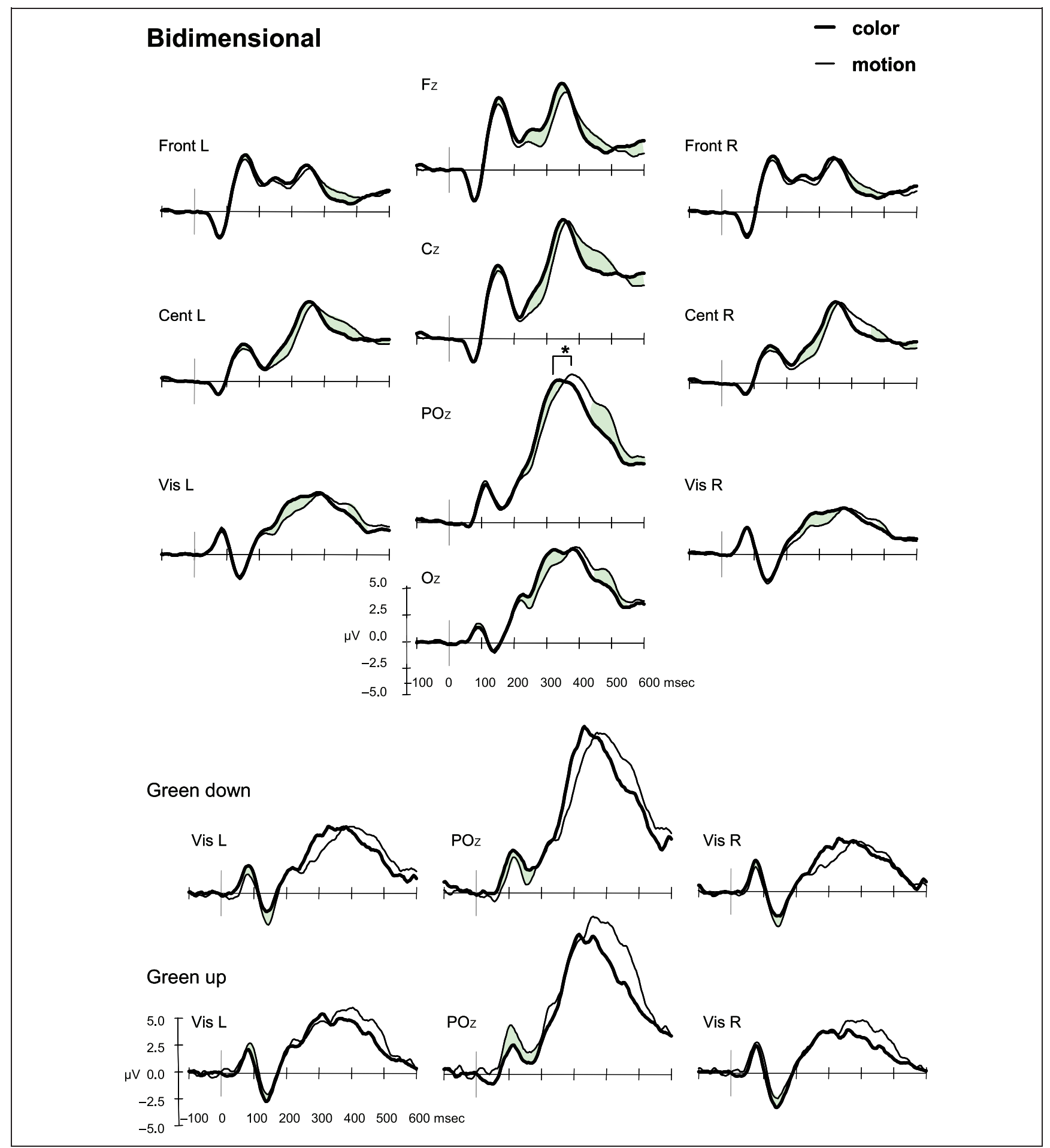

Figure 3. Grand-averaged ERP waveforms for bidimensional stimuli, showing the effects of selective attention to feature dimensions between the motion-dominant and color-dominant blocks. (Top) Grand-averaged ERPs elicited by bidimensional stimuli are averaged over color and motion values in color-dominant (thick lines) versus motion-dominant (thin lines) conditions. Data are shown for representative midline electrodes (Fz, Cz, POz, Oz), and averaged over lateral electrodes in frontal (FP1/2, AF3/4, AF7/8, F3/4, F5/6, F7/8), central (FC1/2, FC3/4, $\mathrm{C} 1 / 2, \mathrm{C} 3 / 4, \mathrm{CP} 1 / 2, \mathrm{CP} 3 / 4)$, and posterior-occipital (PO3/4, PO7/8, O1/2) scalp regions. The same configuration of electrodes is used in all subsequent figures. Positive polarity is plotted upward in this and all subsequent figures. Significant modulations are indicated by shading. (Bottom) Grand-averaged ERPs elicited by the green bidimensional stimuli with downward versus upward motion are plotted separately for the posterior electrodes in order to show the feature-specific effects of attention to color versus motion. For downward stimuli, the P1 component was larger in the color-dominant task, but for upward stimuli, the effect went in the opposite direction. 
$\left.\left.\& \mathrm{D}^{-} \mathrm{F}^{-}\right)\right]$. These effects were also evident in the simple effect of responding to a nonrepeated feature in the dominant versus nondominant dimension $\left(\mathrm{D}^{+} \mathrm{F}^{-}\right.$ vs. $\mathrm{D}^{-} \mathrm{F}^{-}$). The selective attention effects operating at the level of feature dimension were accompanied by the necessity to switch from using the dominant dimension in a task to the other dimension for responding and may therefore have reflected some task-switching operations.

\section{Feature-specific Attention Effects in Motion Stimuli}

The standard analyses of the P1, N1, and P300 components did not reveal any interaction involving dominant dimension and feature repetition factors suggestive of direction-specific attention effects. In contrast, regional analyses revealed that inhibition of a particular motion direction in the previous bidimensional stimulus had clear effects on the ERPs during early perceptual analysis of the subsequent unidimensional stimulus (Figure 4). Negative priming of direction modulated the first identifiable ERP components over frontal (60$120 \mathrm{msec})$ and central $(80-120 \mathrm{msec})$ regions of the scalp, all $F \mathrm{~s}(1,14)>4.6, p<.05$. The negative component elicited over frontal and frontal-central electrodes was markedly reduced when the direction had been previously ignored but in no other condition. This negative-priming effect was confirmed by a post hoc comparison of the mean voltage between 80 and $120 \mathrm{msec}$ in waveforms (averaged over all electrodes in frontal and central regions) elicited by stimuli whose direction of motion was the same as or different than the direction ignored in the previous bidimensional stimulus, $\left(\mathrm{D}^{-} \mathrm{F}^{+}\right.$vs. $\left.\mathrm{D}^{-} \mathrm{F}^{-}\right): t(14)=2.66, p=.02$. An equivalent comparison of waveforms elicited by stimuli whose direction of motion was the same as or different from that selected in the previous bidimensional stimulus showed a small trend for the opposite effect, with the positive-priming effect tending to increase the negative component, $\left(\mathrm{D}^{+} \mathrm{F}^{+}\right.$vs. $\left.\mathrm{D}^{+} \mathrm{F}^{-}\right): t(14)=-1.9$, $p=.08$.

Facilitation of the particular motion direction by previous selection in the bidimensional stimulus was observed only during later aspects of the waveform, mainly in the time period of the P300. The interaction between dominant dimension and feature repetition was significant between 360 and $420 \mathrm{msec}$ at the lateral region, and 380-420 msec at midline and central regions, all $F \mathrm{~s}(1,14)>4.9, p<.05$. Nonrepeated directions elicited more positive components than repeated directions when motion was selected in the previous stimulus. This effect was confirmed by a post hoc comparison of mean voltage between 380 and $420 \mathrm{msec}$ in waveforms (averaged over all electrodes in midline, lateral, and central regions) elicited by stimuli whose direction of motion was the same as or different from that selected in the previous bidimensional stimulus,
$\left(\mathrm{D}^{+} \mathrm{F}^{+}\right.$vs. $\left.\mathrm{D}^{+} \mathrm{F}^{-}\right): t(14)=-2.41, p=.03$. A small effect in the opposite direction occurred when motion was ignored in the previous stimulus, but an equivalent post hoc test revealed this not to be significant, $\left(\mathrm{D}^{-} \mathrm{F}^{+}\right.$ vs. $\left.\mathrm{D}^{-} \mathrm{F}^{-}\right): t(14)=0.82, p=.43$.

\section{Feature-dimension Attention Effects in Motion Stimuli}

Figure 5 shows the effects of attending or ignoring the motion dimension in a given block on ERPs elicited by direction stimuli. The dominant dimension did not alter significantly the mean amplitude of the P1, N1, or P300 components elicited by unidimensional direction stimuli. P300 latency could not be analyzed because it was not always possible to identify a reliable peak in the color-dominant dimension. The P300 peaked around $400 \mathrm{msec}$ in the motion-dominant task, whereas waveforms showed a plateau of positive voltage after $400 \mathrm{msec}$ in the color-dominant task.

Regional analyses showed that waveforms elicited by unidimensional motion stimuli were significantly modulated, starting at $140 \mathrm{msec}$, by whether color or motion was the dominant dimension in the task block, that is, by whether a task-switching operation was required. Waveforms elicited by direction stimuli when motion was the dominant dimension (i.e., when no task-switching operation was required) were more negative after $140 \mathrm{msec}$. The effect was interrupted during the period of the peak of the P300 in the motion-dominant task, but resumed after $460 \mathrm{msec}$. During the early phase, the effect had an extended central distribution, and significant main effects of dominant dimension were obtained over midline (140-320 msec), frontal (140-360 msec), central (140-320 msec), lateral (140-320 msec), and posterior (180-260 msec) regions, all $F \mathrm{~s}(1,14)>4.8$, $p<.05$. During the later phase, the effect had a more posterior distribution, with significant main effects of dominant dimension in midline (480-600 msec), lateral (460-600 msec), and posterior (540-600 $\mathrm{msec}$ ) regions, all $F \mathrm{~s}(1,14)>4.7, p<.05$.

The effects of specific directions in general, independently of the attention conditions, were minor. No main effects of the direction occurred over any scalp region. The direction factor also did not interact with any of the attention effects described above.

\section{Feature-specific Attention Effects in Color Stimuli}

Similarly to motion stimuli, repetition of an ignored feature altered early stages of stimulus processing. The amplitude of the N1 component was affected by featurespecific negative priming (Figure 6). The effect was distributed focally over midline posterior sites, as indicated by the interaction between dominant dimension, feature repetition, and electrode, $F(2.7,38.2)=3.07, p=$ 


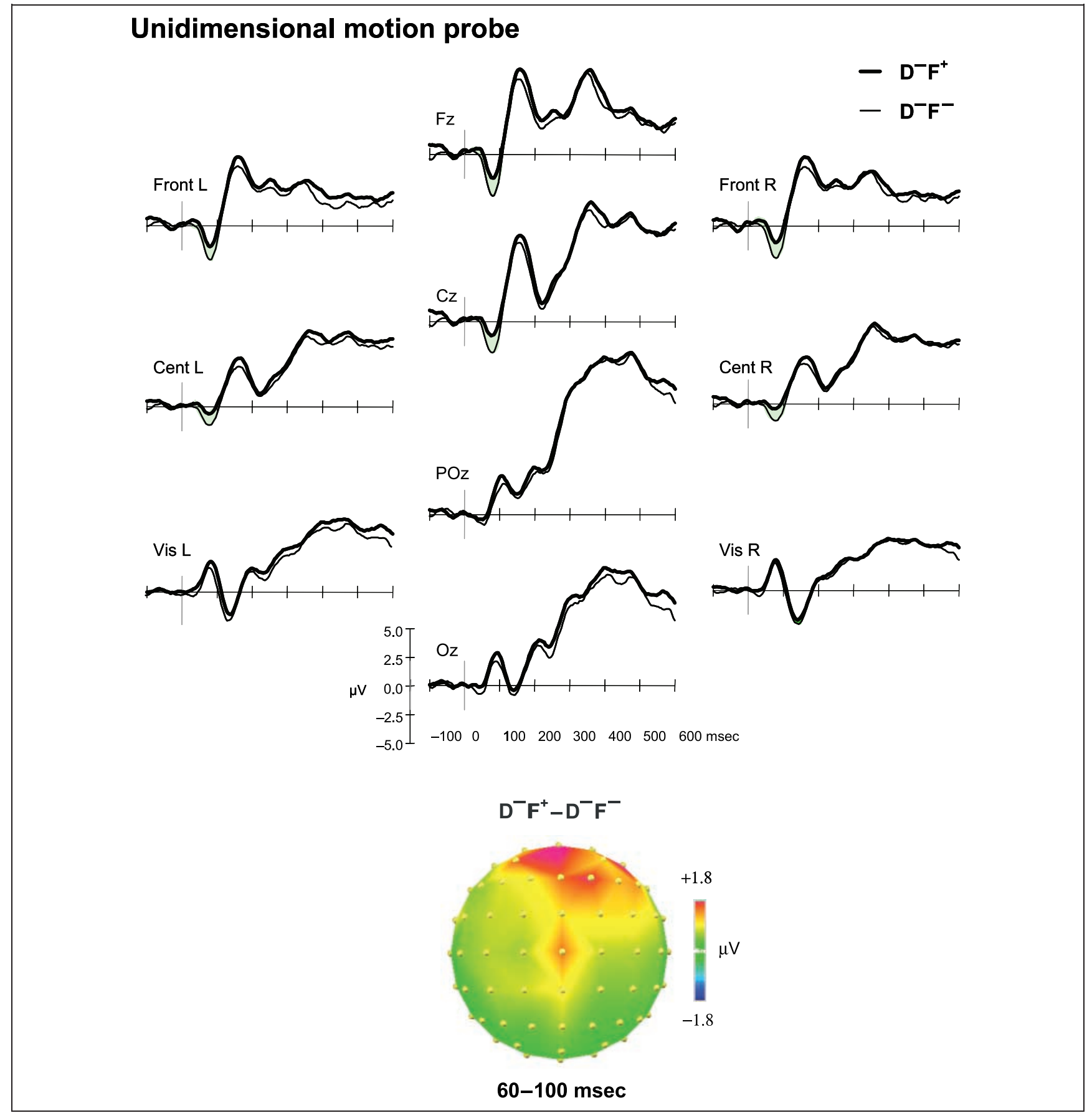

Figure 4. Feature-specific negative-priming effects for unidimensional motion stimuli. (Top) Grand-averaged ERPs elicited by unidimensional motion stimuli (averaged over downward and upward motion values) when the same motion direction was repeated (ignored) in the previous stimulus (thick lines) versus when the other motion direction was ignored (thin lines). Significant motion-specific negative-priming effects occurred during the early part of the waveform, especially over frontal and central electrodes, as indicated by shading. (Bottom) Scalp topography of the significant ERP effect $\left(\mathrm{D}^{-} \mathrm{F}^{+}-\mathrm{D}^{-} \mathrm{F}^{-}\right)$averaged over its duration $(60-100 \mathrm{msec})$. Voltage values were interpolated between electrodes. In this and subsequent figures, maximal positive voltage differences are plotted in red values, whereas maximal negative voltage differences are plotted in blue. The range of the voltage is indicated by the scale bar.

.04. Post hoc $t$ tests indicated that the N1 component was more negative when the specific hue was ignored in the preceding stimulus compared to when the other hue was ignored, $\left(\mathrm{D}^{-} \mathrm{F}^{+}\right.$vs. $\left.\mathrm{D}^{-} \mathrm{F}^{-}\right): t(14)=2.91, p=$ .01. However, the N1 component was not affected when the specific hue was selected in the previous stimulus, $\left(\mathrm{D}^{+} \mathrm{F}^{+}\right.$vs. $\left.\mathrm{D}^{+} \mathrm{F}^{-}\right): t(14)=0.34$.

Feature-specific positive priming did not affect early stages of stimulus analysis, but instead altered the late P300 component. The effect was more pronounced for 
Figure 5. The main effect of attending versus ignoring the motion dimension on ERPs elicited by unidimensional direction stimuli $\left[\left(\mathrm{D}^{+} \mathrm{F}^{+}\right.\right.$\& $\left.\mathrm{D}^{+} \mathrm{F}^{-}\right)$vs. $\left.\left(\mathrm{D}^{-} \mathrm{F}^{+} \& \mathrm{D}^{-} \mathrm{F}^{-}\right)\right]$. (Top) Grand-averaged ERPs elicited by unidimensional motion stimuli averaged over upward and downward motion values when these were repeated or ignored in motion-dominant $\left(\mathrm{D}^{+} \mathrm{F}^{+}\right.$ $\& \mathrm{D}^{+} \mathrm{F}^{-}$, thick lines) versus color-dominant $\left(\mathrm{D}^{-} \mathrm{F}^{+}\right.$\& $\mathrm{D}^{-} \mathrm{F}^{-}$, thin lines) conditions. Significant effects of attention to feature dimensions or switching between relevant and irrelevant dimensions occurred after initial perceptual analysis, as indicated by shading. (Bottom) Scalp topographies of the significant ERP effects $\left[\left(\mathrm{D}^{+} \mathrm{F}^{+}\right.\right.$ $\left.\& \mathrm{D}^{+} \mathrm{F}^{-}\right)$minus $\left(\mathrm{D}^{-} \mathrm{F}^{+} \&\right.$ $\left.\mathrm{D}^{-} \mathrm{F}^{-}\right)$], averaged over their durations (as indicated).

\section{Unidimensional motion probe}
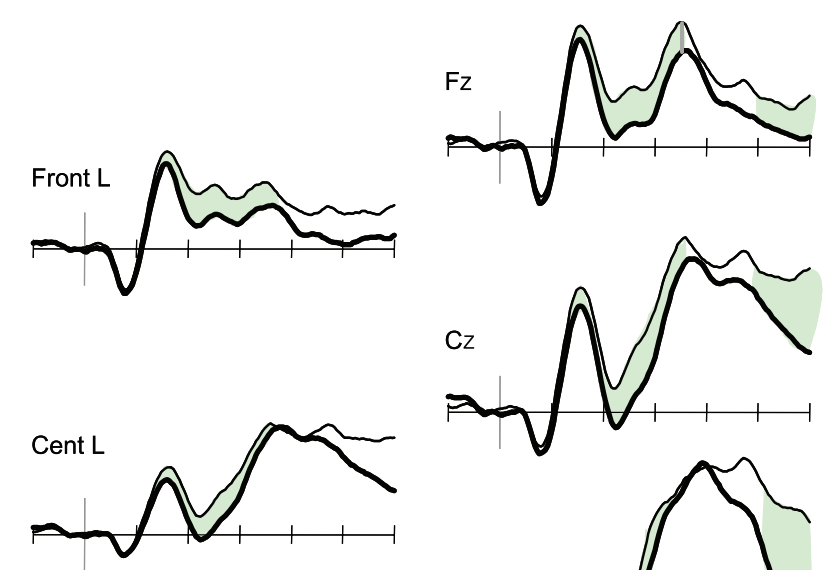

$\mathrm{POz}$
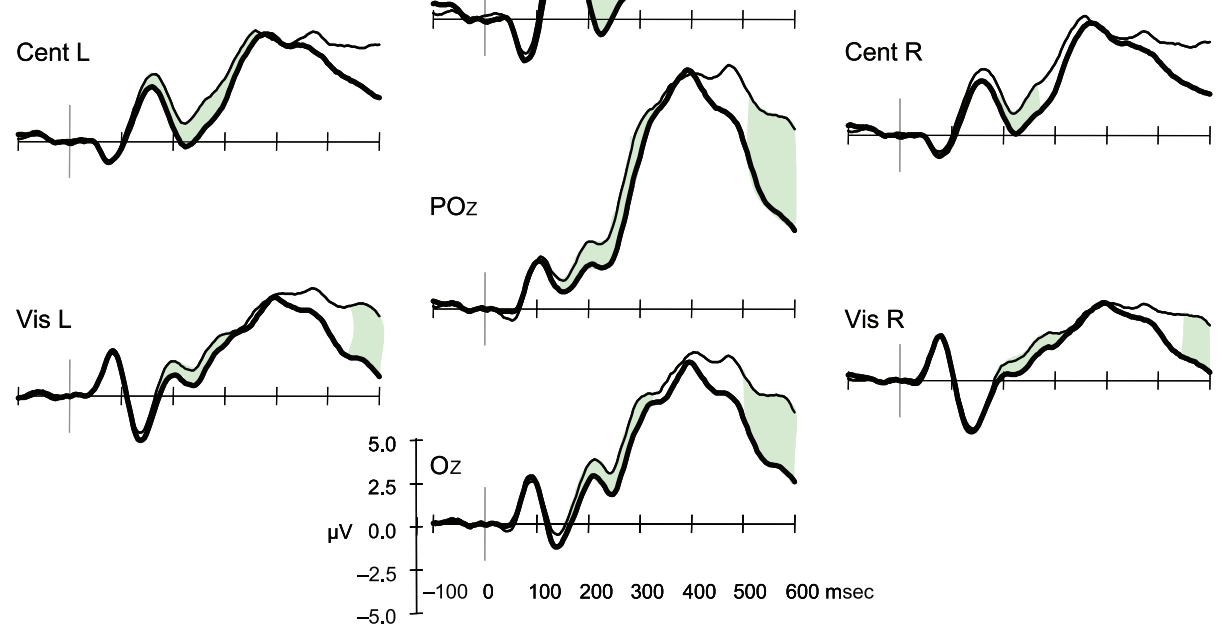

$\left(D^{+} F^{+} \& D^{+} F^{-}\right)-\left(D^{-} F^{+} \& D^{-} F^{-}\right)$

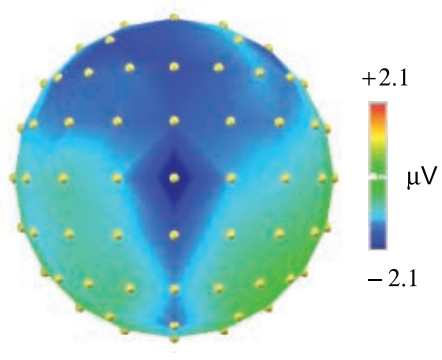

$140-320 \mathrm{msec}$

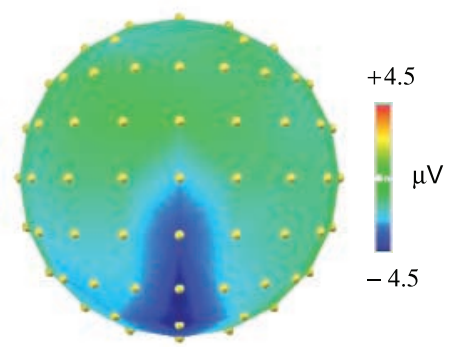

480-600 msec green items, as reflected by an interaction between dominant dimension, repetition, and hue, $F(1,14)=$ $5.71, p=.03$. Post hoc $t$ tests showed that P300 was enhanced for the previously selected hue compared to the other hue in the color-dominant condition, $t(14)=2.32, p=.04$, but was unaffected as a function of inhibition of the specific hue in the previous trial, $t(14)=0.15$.

The regional analyses confirmed the results of the component analyses. The inhibition of the particular color hue in the previous bidimensional stimulus influenced processing in the posterior region during the N1 period (120-160 msec). The effect was distributed focal- ly over the posterior region, appearing as an interaction between dominant dimension, feature repetition, and electrode, $F(1,14)=5.8, p=.02$. The negative posterior potential was larger when the particular hue was previously ignored compared to when the other hue was ignored, as shown by a $t$ test at $\mathrm{Oz}$, where the effect was largest, $t(14)=-2.9, p=.01$. No similar effect of hue repetition occurred when color was the dominant dimension, $t(14)=0.34, p=.74$.

Facilitation of the particular color hue by previous selection in the bidimensional stimulus was observed during later aspects of the waveform, mainly in the period of the P300. The factors of dominant dimension 


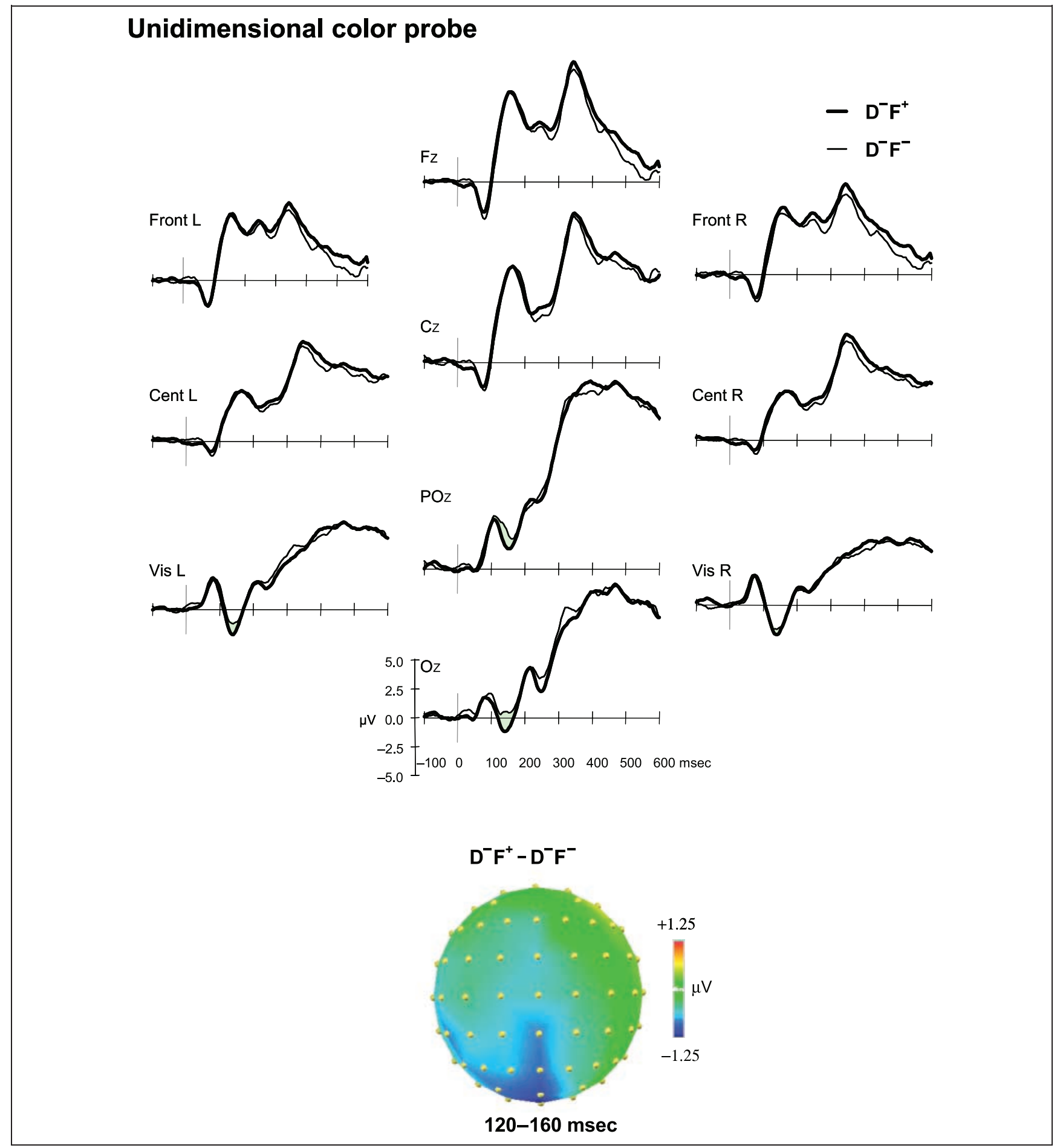

Figure 6. Feature-specific negative-priming effects for unidimensional color stimuli. (Top) Grand-averaged ERPs elicited by unidimensional color stimuli averaged over red and green hue values when the same color hue was ignored in the previous stimulus (thick lines) versus when the other color hue was ignored (thin lines). Significant color-specific negative priming effects occurred during the early part of the waveform, especially over medial occipital electrodes, as indicated by shading. (Bottom) Scalp topography of the significant ERP effect $\left(\mathrm{D}^{-} \mathrm{F}^{+}-\mathrm{D}^{-} \mathrm{F}^{-}\right)$averaged over its duration (120-160 msec).

and feature repetition modulated activity over focal portions of the frontal region $(320-400 \mathrm{msec}$, Dominant Dimension $\times$ Feature Repetition $\times$ Hemisphere $\times$ Electrode), all $F \mathrm{~s}>4.2, p<.05$. A similar effect was obtained at the posterior (360-400, 500-600 msec) region, where the effect also interacted with hue (Dominant Dimension $\times$ Feature Repetition $\times$ Hue $\times$ Electrode), all $F \mathrm{~s}>3.2, p<.05$. 
Feature-dimension Attention Effects in Color Stimuli

Figure 7 shows the effects of attending or ignoring the color dimension on ERPs elicited by hue stimuli. The dominant dimension in a given block of trials did not exert a main effect on the mean amplitude of the visual components. The N1 component appears larger when the task is to attend color (i.e., when no task switching is required), but the effect does not reach statistical significance. Dominant dimension interacted significantly

\section{Unidimensional color probe}
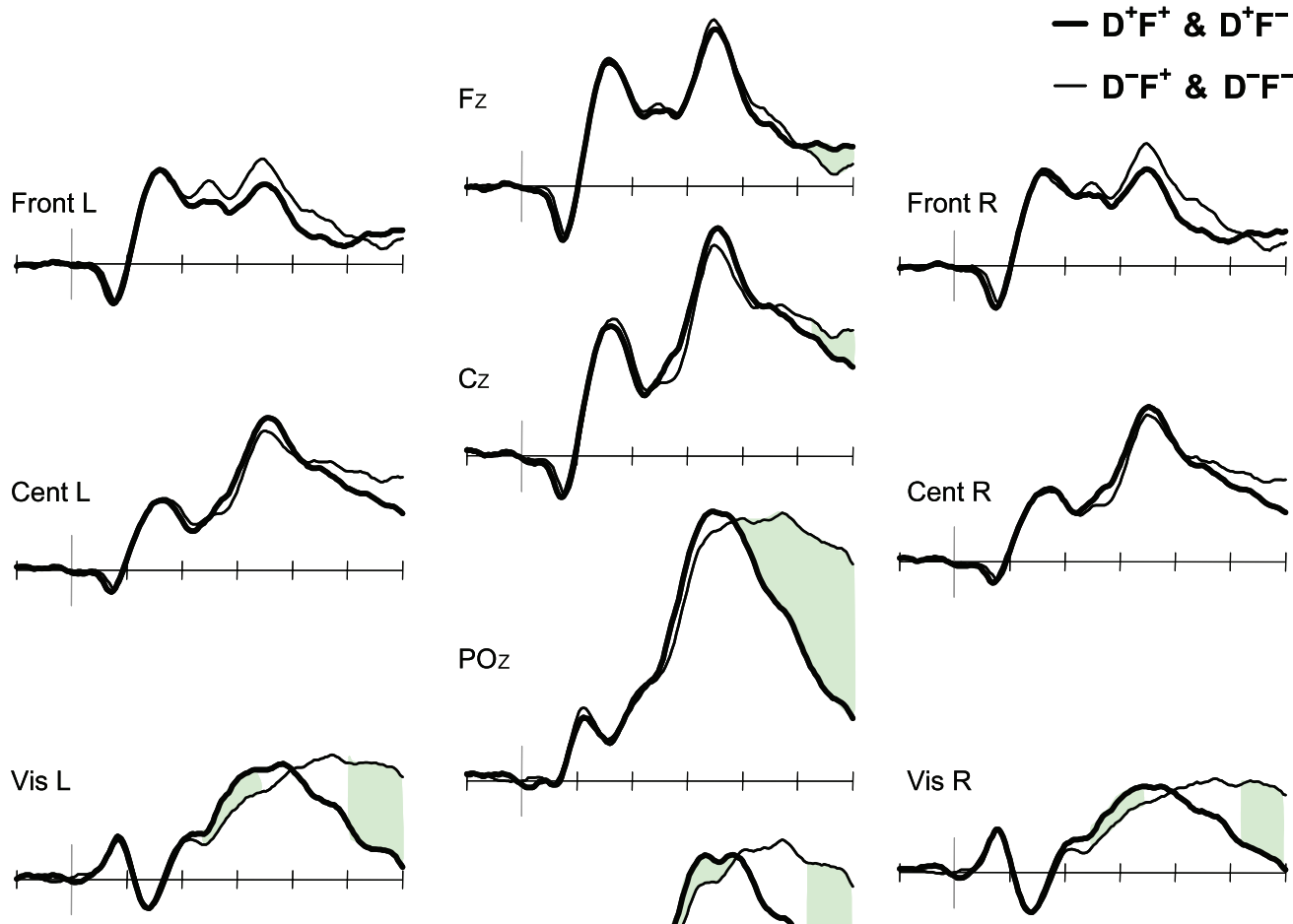

$\left(D^{+} F^{+} \& D^{+} F^{-}\right)-\left(D^{-} F^{+} \& D^{-} F^{-}\right)$

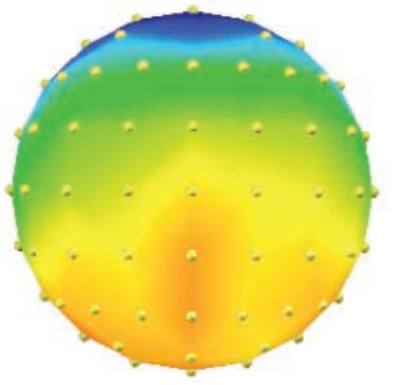

240-320 msec
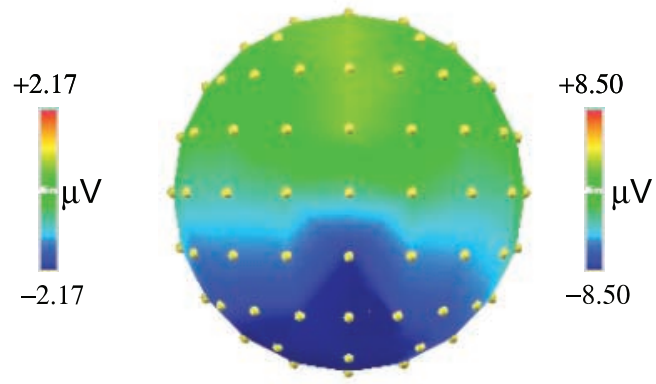

$500-600 \mathrm{msec}$

Figure 7. The main effect of attending versus ignoring the color dimension on ERPs elicited by unidimensional hue stimuli $\left[\left(\mathrm{D}^{+} \mathrm{F}^{+} \& \mathrm{D}^{+} \mathrm{F}^{-}\right)\right.$ vs. $\left(\mathrm{D}^{-} \mathrm{F}^{+} \& \mathrm{D}^{-} \mathrm{F}^{-}\right)$]. (Top) Grand-averaged ERPs elicited by unidimensional hue stimuli averaged over red and green hue values when these were repeated or ignored in color-dominant $\left(\mathrm{D}^{+} \mathrm{F}^{+} \& \mathrm{D}^{+} \mathrm{F}^{-}\right.$, thick lines) versus motion-dominant $\left(\mathrm{D}^{-} \mathrm{F}^{+} \& \mathrm{D}^{-} \mathrm{F}^{-}\right.$, thin lines) condition. Significant effects of attention to feature dimensions or switching between relevant and irrelevant dimensions occurred after initial perceptual analysis, as indicated by shading. (Bottom) Scalp topographies of the significant ERP effects $\left[\left(\mathrm{D}^{+} \mathrm{F}^{+} \& \mathrm{D}^{+} \mathrm{F}^{-}\right)\right.$minus $\left.\left(\mathrm{D}^{-} \mathrm{F}^{+} \& \mathrm{D}^{-} \mathrm{F}^{-}\right)\right]$, averaged over their durations (as indicated). 
with electrode to modulate P300 amplitude, $F(1.1$, 15.6) $=4.36, p=.05$. The P300 components elicited in the color-dominant task were of shorter duration than in the motion-dominant task, leading to a smaller mean amplitude measure, with the effect being largest over Pz. P300 latency could not be analyzed because it was not always possible to identify a reliable peak in the motiondominant task. The P300 peaked around $350 \mathrm{msec}$ in the color-dominant task, whereas waveforms showed a plateau of positive voltage after $350 \mathrm{msec}$ in the motiondominant task.

Regional analyses showed that processing of hue stimuli was affected by whether color was the relevant or irrelevant task dimension in a given trial block after early visual processing. Waveforms elicited by unidimensional color stimuli were significantly modulated by attending color or motion during a block of trials, starting after the N1 component over posterior regions. Waveforms elicited by hue stimuli when color was the dominant dimension (i.e., when no task-switching operation was necessary) were more positive over the posterior scalp region (240-360 msec), all $\mathrm{Fs}(1,14)>4.8$, $p<.05$. After the period of the $\mathrm{P} 300$ peak in the colordominant task, significant main effects of color selection resumed, but with the opposite polarity. Waveforms elicited by hue stimuli when color was the dominant dimension became more negative after the P300 peak, whereas waveforms elicited during the motion-dominant task showed a sustained positive component. These late modulations appeared as main effects of dominantdimension after $500 \mathrm{msec}$ at midline (520-600 msec) and posterior (500-600 msec) regions, all $F \mathrm{~s}(1,14)>4.5$, $p<.05$.

The effects of specific hues in general, independently of the attention conditions, were observed only over late portions of the ERPs (420-520 msec) over midline (440$460 \mathrm{msec})$, central (420-520 msec), and lateral (440$480 \mathrm{msec})$ regions, all $F \mathrm{~s}(1,14)>4.6, p<.05$. The hue factor interacted with the late P300-related modulation of previously selected items, but did not interact with any other attention effects described above.

\section{DISCUSSION}

\section{Behavioral Indices of Attention to Features}

The behavioral findings yielded clear evidence for the ability to direct attention differentially to constituent features of objects, independently of any spatial selection. Participants were able to identify individual features of foveal objects containing competing features with incongruent response assignments with high degree of accuracy. The need to shift attention to the other feature dimension in order to identify single feature values in unidimensional stimuli with a nondominant feature entailed significant performance costs, both in accuracy and in speed of response. These behavioral decrements may have reflected general task-switching costs as well as more specific costs in switching between relevant perceptual dimensions for responding. These costs argue against the automatic bundling of all the attributes within individual objects (Duncan, 1984; Kahneman \& Treisman, 1984) under all circumstances. The assignment of competing features of objects to incongruent responses is sufficient to engage differential attention to feature dimensions.

In addition to costs of switching between different feature dimensions, the results revealed selection processes that acted at the level of individual feature values. Ignoring one feature value (e.g., red) in a bidimensional stimulus impaired the subsequent identification of the same feature value in a unidimensional stimulus relative to the identification of the other feature value in the same dimension (i.e., green). In other words, we obtained evidence for negative priming (Tipper, 1985) at the level of individual feature values. Negative priming occurred for both motion and color, and resulted mainly in reaction-time costs. Positive effects of selecting the same feature value compared to the other feature value in the same dimension were not obtained, although selecting the identical feature value twice was the only condition where the same behavioral response was selected. These findings suggest that inhibition of irrelevant feature values is an active process that can have stronger consequences for subsequent information processing than selecting relevant feature values. These findings offer a replication of the feature-specific negative-priming effects obtained in a previous investigation (Fanini et al., in press) despite several differences in experimental design.

\section{Modulation of Neural Processing by Attention to Features}

ERPs recorded during task performance identified several effects of directing attention to specific feature dimensions or feature values upon neural processing of foveal stimuli, starting from early perceptual analysis.

\section{Selective Attention to Motion or Color in Stimuli with Competing Features}

ERPs revealed that neural processing of the identical foveal stimulus containing two competing feature values was significantly modulated depending on which feature dimension was relevant in a given block of trials. Modulation of the visual components P1 and N1 were further dependent on the specific feature values in the stimulus. Using ERPs alone, one finds it difficult to speculate how these perceptual modulations translate into the underlying neural mechanisms for selecting between competing features of the same object. One 
possibility is that the irrelevant competing feature is filtered out, similar to the mechanisms observed for selecting between locations (Reynolds et al., 1999; Luck et al., 1997; Treue \& Maunsell, 1996; Moran \& Desimone, 1985) or objects (Treue \& Martinez Trujillo, 1999; Chelazzi, Duncan, et al., 1998; Chelazzi, Miller, et al., 1993, 2001) that fall within receptive fields of single neurons. Single-neuron investigations using stimuli with competing feature values will be critical to establish the neuronal mechanisms of this type of feature selection (Caselli et al., 2004).

Attention to one feature dimension also resulted in modulation of later stages of stimulus analysis. When color was relevant, the P300 component peaked significantly earlier than when motion was relevant. The P300 component in visual categorization tasks has been proposed to reflect stimulus evaluation, contextual updating in working memory, or response selection processes (Hermann \& Knight, 2001; Polich, 1998; Verleger, 1997; Picton, 1992; McCarthy \& Donchin, 1981), and to reflect activity in a distributed network of brain areas (He, Lian, Spencer, Dien, \& Donchin, 2001; McCarthy, Luby, Gore, \& Goldman Rakic, 1997; Yamaguchi \& Knight, 1991; Smith et al., 1990; McCarthy, Wood, Williamson, \& Spencer, 1989). The P300 latency effect paralleled the reaction-time effect, with $\mathrm{P} 300$ peak latency preceding the RT by about 46-47 msec. Unlike the perceptual modulations, the specific feature values did not exert a significant effect on the modulation of these later stages of stimulus analysis. Feature-specific information therefore may not be preserved during decision making and response selection. Again, single-unit recordings examining the effects of attention to competing features in individual stimuli in sensorimotor areas involved in decision making and response selection would be very illuminating (Caselli et al., 2004).

\section{Consequences of Ignoring Specific Feature Values}

ERPs showed that ignoring an irrelevant competing feature had specific consequences for the subsequent perceptual analysis of the ignored feature. The behavioral feature-specific negative-priming effect was accompanied by early modulations of the ERPs elicited by unidimensional stimuli whose feature value was previously ignored compared to stimuli containing the other feature value of the ignored dimension.

The modulations did not affect the canonical P1 and N1 visual components. For motion, feature-specific negative priming affected stimulus processing between 60 and 120 msec over frontal and frontal-central scalp regions. The negative frontal component was attenuated when the specific feature value had been previously ignored. The latency and distribution of this effect are puzzling. Motion-related activity in visual areas typically occurs within posterior visual components, starting from the $\mathrm{C} 1$ component with a source in striate visual cortex, and followed by activity in extrastriate areas specialized for motion processing (MT/V5+) starting around 120 msec (Schoenfeld, Heinze, \& Woldorff, 2002). Although visual stimuli have also been shown to elicit an anterior N1 component, which is modulated by attention (Karayanidis \& Michie, 1996), this component occurs much later (peaking around $150 \mathrm{msec}$ ) than that recorded in the present task. It remains possible that the component reflects motion-related processing, which is inhibited by motion-specific negative priming. In this case, the specific parameters in our task, such as the use of foveal stimuli and between-feature competition, may have been more effective than other visual attention tasks at revealing early motion-related processing. Another possibility is that motion-specific negative priming affected early stimulus analysis outside visual areas. For example, early processing in frontal regions could have been affected, in areas capable of affecting ongoing visual processing via feedback connections (Saron, Schroeder, Foxe, \& Vaughan, 2001).

For color, feature-specific negative priming affected processing during the time period of the N1 visual component, between 120 and $160 \mathrm{msec}$, over midline posterior electrodes. The negative component was larger when the specific feature value had been previously ignored. The effect was less lateralized than the N1 component, but was still easily consistent with modulation of early processing in visual areas. This suggests the modulations observed here do not reflect alterations in the neural activity of all the areas that contribute to the N1 component. The N1 most likely reflects activity in several brain areas (Di Russo, Martinez, Sereno, Pitzalis, \& Hillyard, 2002). The effects of color-specific negative priming are likely to involve only a subset of these areas. Ventromedial visual areas in the lingual and fusiform gyri would be good candidates for the effects observed. Intracranial ERP recordings have shown color-specific modulations in this region within the same time range (Allison et al., 1993). Localization of brain activity is notoriously difficult and often tricky with ERPs (Rugg \& Coles, 1995; Allison, Wood, \& McCarthy, 1986). Complementary investigations using brain imaging to identify the source of these feature-specific negative priming effects would be very useful (Saenz et al., 2002).

Whatever the specific source of the neural effects, the findings point to the existence of active inhibitory mechanisms that act upon irrelevant competing features and that have residual action on subsequent stimulus processing. These negative-priming effects were not simply a result of feature repetition. Post hoc statistical tests showed that the early ERP modulations were specific to inhibition of the specific feature relative to the other feature of the same dimension in the preceding trial. Features were also repeated when their dimension was dominant and therefore selected in the previous trial, but, in this case, no early perceptual modulations occurred for either motion or color. 
In contrast to the pronounced early effects of featurespecific negative priming, selecting a dominant feature value had no effect on the early portions of ERP waveforms. Feature values that were repeated and selected in the previous trial engaged equivalent early processing as feature values in the dominant dimension that were not repeated and selected in the previous trial. The effects of feature-specific repetition in the dominant dimension were restricted to the late portion of the ERP waveforms, occurring around the P300 component, for both motion and color. The effects were different in nature for the unidimensional motion and color stimuli, suggesting that multiple modulatory mechanisms may operate at this stage of stimulus analysis.

\section{Consequences of Attention to Feature Dimensions}

Comparing responses to unidimensional stimuli occurring when their feature was in the dominant, attended feature dimension versus in the nondominant, ignored dimension, captured the neural processes involved in tonic dimension selection and in switching between attended dimensions (i.e., switching between attentional task sets; Rushworth, Nobre, \& Passingham, 2005). For example, the processing of a motion value (e.g., upward) when motion was the dominant dimension would have benefited from any effects of attending the motion set during the block, and over at least the last trial (which was always a bidimensional stimulus whose motion was selected). In contrast, the processing of a color stimulus (e.g., red) would have suffered from any effects of inhibiting or filtering out the color dimension during the block and over the last trial. In addition, it would have required a shift of attention from the motion dimension to the color dimension in order for the subject to identify the color value instead of the default motion value. The latter process is a form of "task switching" (Rogers \& Monsell, 1995; Allport et al., 1994; Jersild, 1927), where participants have to shift between performing different tasks based on different stimulus attributes. However, in our case, there are no changes in response assignments to the different features used, and only the feature dimension of relevance changes in a purely stimulus-driven way (Rushworth, Nobre, \& Passingham, 2005).

For both motion and color unidimensional stimuli, effects of dimension selection and dimension shifting occurred after feature-specific attention effects. For motion stimuli, the first effect started around $140 \mathrm{msec}$ and had a widespread distribution maximal over the central scalp region. Waveforms elicited by direction stimuli when motion was the dominant dimension were more negative; when color was the dominant dimension, they were more positive. For color stimuli, the first effect started after the visual components P1 and N1, around $240 \mathrm{msec}$, over midline and lateral posterior scalp regions. Waveforms elicited by hue stimuli when color was the dominant dimension were more positive; when motion was the dominant dimension, they were more negative. Later modulations also occurred and were similar in the case of both motion and color. Whereas identification of a feature in the dominant attended dimension led to a P300 potential with a clear peak, identification of a feature in the nondominant, ignored dimension elicited a sustained positivity over the central and posterior regions of the scalp, which formed a plateau at the end of the recording epoch. None of the effects was specific to the individual feature values.

This pattern of findings suggests that no early perceptual bias in the processing of attended versus ignored dimensions is reflected in the ERP components. There was no enhancement of the P1 or N1 component associated with the processing of features when they occurred in the dominant, attended dimension. Instead, modulations started just after these visual components. Because there is no competing feature in the unidimensional stimuli, the modulations also cannot reflect tonic inhibition of an irrelevant feature. The timing of the first ERP effects is compatible with the engagement of operations required to switch to processing the nondominant feature dimension. The different distributions of the earlier effects show that some of the processes for shifting attention to a nondominant feature dimension may be dimension specific. The similar nature of the later modulations shows that some of the effects may rely on the workings of the same or similar neural networks. Again, the effects within the P300 period parallel the behavioral results. Participants responded much faster when the dimension of the unidimensional stimulus was relevant, which is when the P300 had a clear and earlier peak. The sustained P300 positivity when the irrelevant dimension was selected probably reflected longer lasting and delayed decision making and response selection.

Previous ERP studies of task switching requiring switching between the relevant stimulus feature dimensions to guide responses (color or shape) have shown that when instructive cues appear before an imperative stimulus requiring implementation of a switch, modulation can occur at earlier, perceptual level of analysis (Rushworth, Nobre, and Passinghan, 2005). In the present experiment, unimodal stimuli occurred unpredictably within a given dominant-dimension context, requiring online switching of the relevant feature dimension to drive the response.

\section{Mechanisms and Time Course of Attention to Features}

Overall, the pattern of results suggests that the perceptual effects of feature-based attention operating on the same object reflect mainly the inhibition or filtering of 
the irrelevant competing feature values. Modulation occurs at the level of individual feature values within dimensions before it occurs at the level of feature dimensions. The earliest modulations in processing occurred in two situations: when features competed for attention in bidimensional stimuli and when a specific feature value had been previously ignored in a bidimensional stimulus (negative priming). These two situations capture online and residual inhibition of feature values, respectively. Residual selection and inhibition at the level of feature dimensions was captured by the comparison between nonrepeated feature values in the dominant versus ignored dimension. As noted above, the comparison also targeted the process of shifting attention between dimensions (switching attentional task set). In this case, no early perceptual modulations were observed, with effects starting 80-120 msec later than when inhibition of specific feature values took place. When no inhibition of features or dimensions is involved, as in the comparison of ERPs elicited by repeated versus nonrepeated features in the dominant dimension, only late ERP modulations occurred around the time period of the P300. Positive selection of features and feature dimensions on a trial-by-trial basis, therefore, does not seem to leave a mark on the perceptual processing of stimuli as measured by ERPS.

The time course of the feature-specific attention effects obtained in the present experiment is earlier than that reported for the selection of features when multiple objects with different spatial locations are employed. When stimuli are separated by location, feature selection is observed after spatial selection and is contingent upon it (Anllo Vento et al., 1998; Eimer, 1997; Anllo Vento \& Hillyard, 1996; Hillyard \& Munte, 1984). The spatial framework may be especially useful to guide attentional selection (Nobre, 2004; Treisman \& Gelade, 1980). Through spatial locations, it is possible to maintain features and objects coregistered through the alignment of receptive fields. In the presence of location, therefore, feature selection may take a second seat. However, when spatial location cannot guide selection, as in visual search situations, effects of attention to features can precede effects of spatial attention (Hopf et al., 2004).

In the present experiment, there was no spatial information to guide or influence selection, and features were in direct competition in the same stimulus. In this situation, feature-based selection affects perception from early stages. Early effects of attention in the absence of spatial cues were also obtained in a study where participants monitored the direction of motion in one transparent colored surface while they ignored the direction of motion in the competing surface of a different color (Valdes Sosa et al., 1998; Valdes Sosa, Cobo, \& Pinilla, 1998). Although our experiments differ substantially, they both indicate that attentional modu- lation can affect early perceptual analysis even in the absence of any spatial information.

\section{Implications for Negative Priming}

In the present experiment, the negative-priming paradigm (Tipper, 1985) was invaluable to the investigation of selective attention to feature dimensions and feature values. In turn, our experiment may also shed light on some of the theoretical issues surrounding the mechanisms of negative priming. Initial interpretations of the negative priming effect focused on residual inhibition of the previously ignored stimulus (Tipper, 1985; Neill, 1977). Later, many additional factors have been proposed to contribute to the effect (Tipper, 2001): long-term inhibition of previously ignored stimuli (DeSchepper \& Treisman, 1996), retrieval of incompatible responses to the same stimulus (Neill, Valdes, Terry, \& Gorfein, 1992), mismatch of perceptual information (Park \& Kanwisher, 1994), and temporal uncertainty for distinguishing present from past relevant information (Milliken, Joordens, Merikle, \& Seiffert, 1998).

Although the results based on competition between individual feature values may not generalize fully to the case of competition between complex objects, the present findings show that residual inhibition can be a major determinant of negative priming and show plainly that the unit of selection during negative priming does not have to be an abstract logogen-like representation (Morton, 1969). Simple visual features can compete for attention and result in negative priming with neural modulation at the perceptual level. Long-term effects of negative priming could not be investigated in our experiment because only a small set of stimulus attributes were used (red, green, up, down), with the possibility of extensive proactive interference between trials. The episodic retrieval of incompatible responses on previous trials did not play a role in our task. Negative priming was measured to unidimensional stimuli, whose response assignment was always the same. Memory of the incongruent response assignment in the previous bidimensional stimulus, where the same feature value was ignored, also did not seem to play a role. The ERP effects of feature-specific negative priming occurred early during stimulus analysis, more in line with modulation of perceptual processing. Mismatch of perceptual information of different objects or attributes that appear in the same location also cannot account for the present effects. All objects and their constituent features occurred in the same foveal location. Furthermore, any effects of perceptual mismatch should affect processing of stimuli in the dominant and ignored dimensions to a comparable extent. This was not the case. Repetition of feature values in the ignored dimension led to performance costs and early ERP modulation, 
whereas repetition of feature values in the dominant dimension lead to no performance changes and only late ERP modulation. The early time course of the ERP effects associated with feature-specific negative priming also poses a challenge for explanations based on temporal uncertainty about distinguishing present from past information.

Our results are most compatible with the action of residual inhibitory mechanisms to suppress irrelevant stimulus attributes. The suppression is guided by conflict posed by the assignment of incongruent responses to the competing attributes. Top-down signals bias processing against irrelevant information (Desimone \& Duncan, 1995). When the attributes in competition are individual visual feature values, the suppression occurs during visual perceptual analysis. It is likely that if the attributes in competition were abstract, such as lexical/ semantic representations of words and pictures (Tipper \& Driver, 1988), the suppression would occur during later phases of stimulus processing. Based on findings with single-unit recordings, it is likely that the extent of suppression of the irrelevant attribute is reactive, which is determined by the strength of the competition between the attributes (Reynolds et al., 1999). Our interpretation is consistent with the Houghton-Tipper model proposed for negative priming (Houghton \& Tipper, 1994).

\section{Summary and Future Directions}

The present experiment has established that selective attention can operate at the level of individual features within an object, independently of any spatial information. Behavioral results showed significant costs to switch between the perceptual dimensions of the object for identification. Furthermore, ignoring a feature in an object caused a residual impairment in identifying that same feature value in a subsequent object. Thus, the results showed that inhibitory effects of selective attention can operate at the level of feature dimensions and individual feature values. ERPs recorded during task performance showed that attentional modulation that occurred early during stimulus processing, during perceptual analysis, reflected mainly inhibitory mechanisms. Early effects occurred when irrelevant features competed for attention during the discrimination of bidimensional stimuli, or when the feature in a unidimensional stimulus was previously ignored.

In the present experiment, constituent features of objects were placed in direct competition by assigning different responses to each feature value. It will be important to determine to what extent response incompatibility drives the attentional selection observed. It is possible that the feature-specific negative priming is only obtained when competing features are assigned to incongruent responses (Fanini et al., in press). If the com- peting feature is not assigned to any response or is assigned to the same response, no feature-specific negative priming may be observed. Future experiments are under way to ascertain the contribution of response conflict in determining the behavioral effects of feature selection and the neural modulation at the early perceptual level.

The particular type of competing features may also be an important determinant of the effects of featurebased attention. In the present experiment, the competing features were color and motion. These are known to rely on distinct functionally specialized visual areas, in different streams of processing (Felleman \& Van Essen, 1991; Mishkin \& Ungerleider, 1982). It is possible that different effects of attentional selection would be obtained if competing features were processed by partly overlapping brain areas and streams. In a previous behavioral experiment using color and orientation as the competing features (Fanini et al., in press), behavioral effects of feature-specific negative priming were also observed, suggesting that the mechanisms for feature selection may be general. Future experiments recording ERPs with attention directed to different combinations of features will be particularly interesting.

Finally, the present experiment concentrated on the modulation of processing feature dimensions and feature values. It should also be possible to investigate the control systems that orient attention to one feature dimension/feature over another. Attention can be directed to a specific feature dimension on a trial-by-trial basis (Fanini et al., in press) using symbolic cues that are equated in physical appearance across participants (Nobre, Sebestyen, \& Miniussi, 2000; Miniussi, Wilding, Coull, \& Nobre, 1999). Of particular interest will be the extent of overlap in neural processing between orienting to feature dimensions and orienting to spatial locations. Brain imaging studies to date have emphasized the commonality of brain areas involved in control of attention to spatial locations, objects, and features (Giesbrecht et al., 2003; Liu et al., 2003; Yantis \& Serences, 2003; Kastner \& Ungerleider, 2000; Pollmann, Weidner, Muller, \& von Cramon, 2000; Wojciulik \& Kanwisher, 1999), although other interpretations are still tenable (Nobre, 2001, 2004).

\section{METHODS}

\section{Participants}

Twenty healthy individuals participated as paid volunteers. All volunteers reported having no neurological disorders. Their visual acuity was normal or corrected to normal. Data from five subjects were discarded because of excessive artifactual trials in the electroencephalogram (EEG) recordings. The remaining 15 subjects ( 7 women) were all right handed ( $85 \%$ mean score 
on the Edinburgh inventory; Oldfield, 1971) and aged between 19 and 38 years.

\section{Task}

Participants discriminated either the color hue or the motion direction of visual stimuli presented briefly and sequentially at the center of gaze (see Figure 1). Foveal stimuli were small square gratings $\left(2^{\circ}\right.$ width) presented briefly (150 msec duration). Gratings consisted of three horizontal and three vertical stripes, each approximately $2^{\circ}$ in length and $0.3^{\circ}$ in width. The distance between adjacent stripes was also $0.3^{\circ}$. Gratings could contain relevant values either in one feature dimension only (unidimensional color or motion stimuli) or in both dimensions (bidimensional color and motion stimuli). Unidimensional color stimuli were either red or green gratings that remained stationary. The values for red and green luminance were adjusted using flicker photometry to ensure equivalent subjective brightness (Kaiser \& Boynton, 1996). Unidimensional motion stimuli were gray gratings, isoluminant with the colored stimuli, whose horizontal lines moved either up or down within the square area ( $9.8^{\circ}$ per second). Bidimensional stimuli were both colored and contained internal movement. In total, there were four types of unidimensional stimuli (red, green, up, down) and four types of bidimensional stimuli (red/up, red/down, green/up, green/down). In the case of moving stimuli, motion onset started immediately upon stimulus appearance.

Each color and motion value was assigned to one specific response of a four-alternative response box. The index and long fingers of each hand were used to deliver responses. Four sets of response assignments were counterbalanced among the participants, with each value of one dimension always assigned to the index finger of one hand and the long finger of the other. For example, one assignment going from the long finger of the left to right hand was red, up, green, down.

Selective attention to feature dimensions was manipulated between short experimental blocks, each lasting 90 trials. At the beginning of each block, participants were instructed that a particular dimension had priority over the other. For example, in a motion-selection block they were specifically instructed: "In this block MOTION wins." Because each feature value had a different response assignment, all bidimensional stimuli contained two possible competing and incongruent responses. In the case of these bidimensional stimuli, where the hue and direction of the stimuli compete for different responses, the relevant dimension trumped the other. In the case of unidimensional stimuli, where only one response is afforded, the participant responded according to the single feature value available.

Participants completed 24 blocks. The order of relevant dimensions was random. Each experimental block contained 90 stimuli (i.e., trials) presented in a quasi- random order. The randomization process was constrained to enhance the probabilities of the stimulus sequences that were of direct relevance to the experimental question. In particular, we were interested in three types of stimulus sequences. (1) Bidimensional stimuli that followed other bidimensional stimuli enabled the investigation of selective attention when feature dimensions compete for responses within a single stimulus object and location (dimension selection). Bidimensional stimuli following unidimensional stimuli were not used to avoid any contributing effects of having to switch between the attended dimensions (e.g., a bidimensional stimulus in a motion-wins block that followed a unidimensional color stimulus). (2) Unidimensional stimuli that followed bidimensional stimuli enabled the investigation of selective attention effects on individual feature values within dimensions (feature selection). Unidimensional stimuli of the ignored, nondominant dimension (e.g., a red color stimulus in a motion-wins block) could be compared when the same feature value (red) had been previously ignored in the preceding bidimensional stimulus versus when the other feature value (green) had been previously ignored. This provides an analogue of negative priming (Tipper, 1985) at the basic level of individual features (Fanini et al., in press). Unidimensional stimuli of the attended dimension (e.g., a red color stimulus in a color-wins block) could be compared when the same feature value (red) had been previously selected in the preceding bidimensional stimulus versus when the other feature value (green) had been previously selected. This provides a measure of facilitatory positive priming at the singlefeature level. Although in this case alone, there is also a difference in the repetition of the same response for a repeated feature value. (3) Finally, unidimensional stimuli that followed bidimensional stimuli also enabled us to examine how stimuli were processed when their feature was in the relevant versus irrelevant dimension (dimension switching). Depending on the block condition (motion-wins vs. color-wins), the feature of the unidimensional stimulus (e.g., motion) is either attended or ignored. When the unidimensional stimulus contains an irrelevant feature (e.g., color in the motion-wins condition), the participant has to switch from discriminating values in the relevant feature dimension (motion direction) to discriminating values in the irrelevant dimension (color hue). These dimension-selection effects on unidimensional stimuli thus also reflect operations of switching attention between feature dimensions.

Each trial began with a fixation mark at the center of the monitor for a variable random delay (250-600 msec). Stimuli appeared for $150 \mathrm{msec}$. Subjects responded as rapidly as possible, while avoiding mistakes, within a window of 150-1300 msec. No feedback was presented if the response was correct. If the response was incorrect or occurred outside the response window, a tone was presented after $100 \mathrm{msec}$ of response delivery. The next 
trial started 100 msec after the response or immediately after the tone (see Figure 1).

The reaction-time and accuracy data were analyzed using repeated-measures analyses of variance (ANOVAs). For bidimensional stimuli, the factors tested were the dominant dimension (color-task, motion-task), their constituent hue (red, green), and their constituent direction (up, down). For unidimensional stimuli, the factors tested were dominant feature dimension, feature repetition, and constituent feature value. The dominantdimension factor in this case was whether the single feature in the stimulus occurred in the attended, dominant dimension $\left(\mathrm{D}^{+}\right)$or not $\left(\mathrm{D}^{-}\right)$in the given trial block. The feature-repetition factor was whether the specific hue or direction was the same as $\left(\mathrm{F}^{+}\right)$or different $\left(\mathrm{F}^{-}\right)$from the preceding bidimensional stimulus. The factors for color stimuli were dominant dimension, feature repetition, and specific hue (red, green). The factors for motion stimuli were dominant dimension, feature repetition, and specific direction (up, down).

\section{Procedures}

Participants received written instructions about the task, after which they could clarify any remaining doubts with the experimenter. Before the placement of electrodes, they completed two to four experimental blocks of trials (90 stimuli in each) to become familiar and competent with the task. Following the placement of the electrodes, participants sat in an armchair within a dimly illuminated and electrically shielded room, facing a computer monitor placed $100 \mathrm{~cm}$ in front of them. They were instructed to maintain visual gaze on the central fixation point and to restrain from blinking during active task periods. Short 5-sec breaks were introduced within experimental blocks to enable participants to rest their eyes and to blink. During the breaks, the name of the relevant dimension (motion or color) appeared in the center of the screen as a reminder, flanked by digits above and below that indicated the number of seconds remaining for the task to resume. The entire experimental session lasted about $2 \mathrm{hr}$, including practice, setup, and task completion.

\section{Event-related Potentials}

The EEG was recorded continuously from 58 sites using tin electrodes mounted on an elastic cap (Electro-cap Inc., Ohio) and positioned according to the 10-20 International System (American Electroencephalographic Society, 1991). The montage included 8 midline sites (FPz, Fz, FCz, Cz, CPz, Pz, POz, Oz) and 25 sites over each hemisphere (FP1/FP2, AF3/AF4, AF7/AF8, F3/F4, F5/F6, F7/F8, FC1/FC2, FC3/FC4, FC5/FC6, FT7/FT8, $\mathrm{C} 1 / \mathrm{C} 2, \mathrm{C} 3 / \mathrm{C} 4, \mathrm{C} 5 / \mathrm{C} 6, \mathrm{~T} 7 / \mathrm{T} 8, \mathrm{CP} 1 / \mathrm{CP} 2, \mathrm{CP} 3 / \mathrm{CP} 4, \mathrm{CP} 5 /$ CP6, TP7/TP8, P1/P2, P3/P4, P5/P6, P7/P8, PO3/PO4,
PO7/PO8, O1/O2). The midline electrode between FPz and $\mathrm{Fz}$ served as the ground site. Voltage from scalp electrodes was referenced to the right mastoid online. Recordings obtained from the left mastoid electrode were used off-line to re-reference the scalp recordings to the average of the left and right mastoids. Electrooculogram (EOG) activity was measured bipolarly. Electrodes placed to the side of each eye measured the horizontal EOG, and electrodes above and below the left eye measured the vertical EOG. The EEG and EOG signals were amplified 20,000 times and digitized at a sampling rate of $250 \mathrm{~Hz}$. Data were recorded with a band-pass filter of 0.03-100 Hz. Digital codes were sent from the stimulus-presentation computer to mark the onset and type of each stimulus.

The EEG was segmented off-line into epochs starting $50 \mathrm{msec}$ before and ending $600 \mathrm{msec}$ after stimulus onset. Trials were discarded if the voltage exceeded \pm $50 \mu \mathrm{V}$ at EOG channels or $\pm 100 \mu \mathrm{V}$ at any other channel. Trials containing behavioral errors were also discarded. To maintain an acceptable signal-to-noise ratio, a lower limit of 15 artifact-free trials per subject per condition was set. Data from five subjects were consequently excluded.

Separate ERP waveforms were constructed for the different attention conditions for bidimensional stimuli, unidimensional color stimuli, and unidimensional motion stimuli. Eight ERP waveforms were constructed for bidimensional stimuli-according to the dominant dimension (color-task, motion-task) and the constituent hue and direction of the stimulus (red/up, red/down, green/up, green/down). Eight ERP waveforms were constructed for the unidimensional color stimuli-according to the dominant dimension (color-task or motion-task), to feature repetition (same or different hue as in preceding bidimensional stimulus), and according to the specific constituent hue (red or green). Eight ERP waveforms were constructed for the unidimensional motion stimuli-according to the dominant dimension (colortask or motion-task), to feature repetition (same or different motion as in preceding bidimensional stimulus), and according to the specific constituent direction value (up or down).

Because of the different physical appearance of the stimulus types, unidimensional color and unidimensional motion stimuli were analyzed separately. Modulations of the ERP waveforms were analyzed using repeatedmeasures ANOVAs. The Greenhouse-Geisser epsilon correction factor was applied to account for possible effects of nonsphericity where appropriate (Jennings \& Wood, 1976). Only corrected probability values and degrees of freedom are reported.

Statistical analyses of ERP waveforms paralleled the analyses of behavioral RT data. However, in addition to the experimental factors in the task, factors pertaining to recording sites were also tested. Waveforms elicited by bidimensional stimuli were tested for the effects of 
the dominant dimension (color-task, motion-task), their constituent hue (red, green), their constituent direction (up, down), scalp hemisphere where applicable, and electrode site. For the unidimensional stimuli, the statistical factors were dominant dimension, feature repetition, feature value (specific hue or specific direction), hemisphere where applicable, and electrode site.

The statistical effects of the experimental variables were tested on standard visual ERP components P1 and N1, and on the late positive component P300. Visual components were measured at the posterior electrode sites Oz, O1, O2, POz, PO3, PO4, PO7, and PO8. P1 was measured as the mean voltage value between 60 and $100 \mathrm{msec}$, and N1 was measured as the mean voltage value between 120 and 160 msec. Both mean voltage and peak latency of the P300 were measured between 300 and $500 \mathrm{msec}$ at central-posterior sites $\mathrm{CPz}, \mathrm{Pz}$, and $\mathrm{POz}$.

In addition to the analyses of specific components, we explored the time course and distribution of effects on bidimensional and unidimensional stimuli using successive mean voltage values every $20 \mathrm{msec}$ between 0 and $600 \mathrm{msec}$ at five different regions of the scalp. The midline region contained seven electrode sites $(\mathrm{Fz}$, $\mathrm{FCz}, \mathrm{Cz}, \mathrm{CPz}, \mathrm{Pz}, \mathrm{POz}, \mathrm{Oz})$. Lateral regions contained six pairs of homologous electrodes across hemispheres: frontal (FP1/FP2, AF3/AF4, AF7/AF8, F3/F4, F5/F6, F7/ F8), central (FC1/FC2, FC3/FC4, C1/C2, C3/C4, CP1/CP2, CP3/CP4), temporal (FC5/FC6, FT7/FT8, C5/C6, T7/T8, CP5/CP6, TP7/TP8), posterior (P3/P4, P5/P6, P7/P8, PO3/ $\mathrm{PO} 4, \mathrm{PO} 7 / \mathrm{PO} 8, \mathrm{O} 1 / \mathrm{O} 2)$. Because of the risk of falsepositive effects in the multiple interrelated comparisons in the regional analyses, results were only considered significant if they persisted over at least two successive time bins in a given region (i.e., $\geq 40 \mathrm{msec}$ ).

\section{Acknowledgments}

The authors thank Heather Jordan for programming the task. We are also grateful to Rebecca Saxe, Alessandra Fanini, and Hendrikje Nienborg, who contributed substantively to previous investigations that helped shape the present experiment. This research was primarily supported by grants to A. C. N. and L. C. from the McDonnell Pew Program in Cognitive Neuroscience. L. C. also acknowledges the generous support from the Human Frontier Science Program (HFSP) and the Italian Government (MIUR).

Reprint requests should be sent to Anna Christina Nobre, Department of Experimental Psychology, University of Oxford, South Parks Road, Oxford, UK, or via e-mail: kia.nobre@psy.ox. ac.uk.

\section{REFERENCES}

Allison, T., Begleiter, A., McCarthy, G., Roessler, E., Nobre, A. C., \& Spencer, D. D. (1993). Electrophysiological studies of color processing in human visual cortex. Electroencephalography and Clinical Neurophysiology, $88,343-355$.
Allison, T., Wood, C. C., \& McCarthy, G. (1986). The central nervous system. In M. G. H. Coles, E. Donchin, \& S. W. Porges (Eds.), Psychophysiology: Systems, processes, and applications (pp. 5-25). New York: Guilford Press.

Allport, D. A., Styles, E. A., \& Hsieh, S. (1994). Shifting intentional set: Exploring the dynamic control of tasks. In C. Umilta \& M. Moscovitch (Eds.), Attention and performance (vol. 15, pp. 421-452). Cambridge: MIT Press.

American Electroencephalographic Society. (1991). American Electroencephalographic Society guidelines for standard electrode position nomenclature. Journal of Clinical Neurophysiology, 8, 200-202.

Anllo Vento, L., \& Hillyard, S. A. (1996). Selective attention to the color and direction of moving stimuli: Electrophysiological correlates of hierarchical feature selection. Perception \& Psychophysics, 58, 191-206.

Anllo Vento, L., Luck, S. J., \& Hillyard, S. A. (1998). Spatio-temporal dynamics of attention to color: Evidence from human electrophysiology. Human Brain Mapping, 6, 216-238.

Baylis, G. C., \& Driver, J. (1993). Visual attention and objects: Evidence for hierarchical coding of location. Journal of Experimental Psychology: Human Perception and Performance, 19, 451-470.

Blaser, E., Pylyshyn, Z. W., \& Holcombe, A. O. (2000). Tracking an object through feature space. Nature, 408, 196-199.

Boussaoud, D., \& Wise, S. P. (1993). Primate frontal cortex: Neuronal activity following attentional versus intentional cues. Experimental Brain Research, 95, 15-27.

Buechel, C., Josephs, O., Rees, G., Turner, R., Frith, C. D., \& Friston, K. J. (1998). The functional anatomy of attention to visual motion. A functional MRI study. Brain, 121, 1281-1294.

Caselli, L., Fanini, A., Bertini, G., Tanaka, H., Mirabella, G., \& Chelazzi, L. (2004). Posterior parietal cortex and the control of non-spatial attention. Abstract Viewer and Itinerary Planner. Washington, DC: Society for Neuroscience, Program No. 331.4.

Chawla, D., Rees, G., \& Friston, K. J. (1999). The physiological basis of attentional modulation in extrastriate visual areas. Nature Neuroscience, 2, 671-676.

Chelazzi, L., Duncan, J., Miller, E. K., \& Desimone, R. (1998). Responses of neurons in inferior temporal cortex during memory-guided visual search. Journal of Neurophysiology, 80, 2918-2940.

Chelazzi, L., Miller, E. K., Duncan, J., \& Desimone, R. (1993). A neural basis for visual search in inferior temporal cortex [see comments]. Nature, 363, 345-347.

Chelazzi, L., Miller, E. K., Duncan, J., \& Desimone, R. (2001). Responses of neurons in macaque area V4 during memory-guided visual search. Cerebral Cortex, 11, 761-772.

Cohen, A., \& Shoup, R. (1997). Perceptual dimensional constraints in response selection processes. Cognitive Psychology, 32, 128-181.

Connor, C. E., Preddie, D. C., Gallant, J. L., \& Van Essen, D. C. (1997). Spatial attention effects in macaque area V4. Journal of Neuroscience, 17, 3201-3214.

Corbetta, M., Miezin, F. M., Shulman, G. L., \& Petersen, S. E. (1991). Selective attention modulates extrastriate visual regions in humans during visual feature discrimination and recognition. Ciba Foundation Symposium, 163, 165-175; discussion 175-180.

Coull, J. T., \& Nobre, A. C. (1998). Where and when to pay attention: The neural systems for directing attention to spatial locations and to time intervals as revealed by both PET and fMRI. Journal of Neuroscience, 18, 7426-7435. 
DeSchepper, B., \& Treisman, A. (1996). Visual memory for novel shapes: Implicit coding without attention. Journal of Experimental Psychology: Learning, Memory, and Cognition, 22, 27-47.

Desimone, R., \& Duncan, J. (1995). Neural mechanisms of selective visual attention. Annual Review of Neuroscience, 18, 193-222.

DeYoe, E. A., \& Van Essen, D. C. (1988). Concurrent processing streams in monkey visual cortex. Trends in Neurosciences, 11, 219-226.

Di Russo, F., Martinez, A., Sereno, M. I., Pitzalis, S., \& Hillyard, S. A. (2002). Cortical sources of the early components of the visual evoked potential. Human Brain Mapping, 15, 95-111.

Duncan, J. (1984). Selective attention and the organization of visual information. Journal of Experimental Psychology: General, 113, 501-517.

Duncan, J., Humphreys, G., \& Ward, R. (1997). Competitive brain activity in visual attention. Current Opinion in Neurobiology, 7, 255-261.

Eimer, M. (1997). An event-related potential (ERP) study of transient and sustained visual attention to color and form. Biological Psychology, 44, 143-160.

Eriksen, B. A., \& Eriksen, C. W. (1974). Effects of noise letters upon the identification of a target letter in a nonsearch task. Perception and Psychophysics, 16, 143-149.

Fanini, A., Nobre, A. C., \& Chelazzi, L. (in press). Selecting and ignoring the component features of a visual object: A negative priming paradigm. Visual Cognition.

Felleman, D. J., \& Van Essen, D. C. (1991). Distributed hierarchical processing in the primate cerebral cortex. Cerebral Cortex, 1, 1-47.

Giesbrecht, B., Woldorff, M. G., Song, A. W., \& Mangun, G. R. (2003). Neural mechanisms of top-down control during spatial and feature attention. Neuroimage, 19, 496-512.

Griffin, I. C., Miniussi, C., \& Nobre, A. C. (2001). Orienting attention in time. Frontiers in Bioscience, 6, D660-671.

Haenny, P. E., Maunsell, J. H., \& Schiller, P. H. (1988). State dependent activity in monkey visual cortex. II. Retinal and extraretinal factors in V4. Experimental Brain Research, 69, 245-259.

Haenny, P. E., \& Schiller, P. H. (1988). State dependent activity in monkey visual cortex. I. Single cell activity in V1 and V4 on visual tasks. Experimental Brain Research, 69, 225-244.

He, B., Lian, J., Spencer, K. M., Dien, J., \& Donchin, E. (2001). A cortical potential imaging analysis of the P300 and novelty P3 components. Human Brain Mapping, 12, 120-130.

Heinze, H. J., Mangun, G. R., Burchert, W., Hinrichs, H., Scholz, M., Munte, T. F., Gos, A., Scherg, M., Johannes, S., Hundeshagen, H., Gazzaniga, M. S., \& Hillyard, S. A. (1994). Combined spatial and temporal imaging of brain activity during visual selective attention in humans. Nature, 372, 543-546.

Hermann, C. S., \& Knight, R. T. (2001). Mechanisms of human attention: Event-related potentials and oscillations. Neuroscience and Biobehavioral Reviews, 25, 465-476.

Hillyard, S. A., \& Munte, T. F. (1984). Selective attention to color and location: An analysis with event-related brain potentials. Perception \& Psychophysics, 36, 185-198.

Hopf, J. M., Boelmans, K., Schoenfeld, M. A., Luck, S. J., \& Heinze, H. J. (2004). Attention to features precedes attention to locations in visual search: Evidence from electromagnetic brain responses in humans. Journal of Neuroscience, 24, 1822-1832.
Houghton, G., \& Tipper, S. P. (1994). A model of inhibitory mechanisms in selective attention. In D. Dagenbach (Ed.), Inbibitory processes in attention, memory, and language (pp. 53-112). San Diego: Academic Press.

Jennings, J. R., \& Wood, C. C. (1976). Letter: The epsilon-adjustment procedure for repeated-measures analyses of variance. Psychophysiology, 13, 277-278.

Jersild, A. T. (1927). Mental set and shift. Archives of Psychology, 14, No. 89, 81.

Kahneman, D., \& Henik, A. (1981). Perceptual organization and attention. In M. Kubovy \& J. R. Pomerantz (Eds.), Perceptual organization (pp. 181-211). Hillsdale, NJ: Erlbaum.

Kahneman, D., \& Treisman, A. (1984). Changing views of attention and automaticity. In R. Parasuraman \& R. Davies (Eds.), Varieties of attention (pp. 29-62). New York: Academic Press.

Kaiser, P. K., \& Boynton, R. M. (1996). Human color vision. Washington, DC: Optical Society of America.

Kanwisher, N., Driver, J., \& Machado, L. (1995). Spatial repetition blindness is modulated by selective attention to color or shape. Cognitive Psychology, 29, 303-337.

Karayanidis, F., \& Michie, P. T. (1996). Frontal processing negativity in a visual selective attention task.

Electroencephalography and Clinical Neurophysiology, 99, 38-56.

Kastner, S., \& Ungerleider, L. G. (2000). Mechanisms of visual attention in the human cortex. Annual Review of Neuroscience, 23, 315-341.

Krummenacher, J., Mueller, H. J., \& Heller, D. (2001). Visual search for dimensionally redundant pop-out targets: Evidence for parallel-coactive processing of dimensions. Perception and Psychophysics, 63, 901-917.

Lavie, N. (1995). Perceptual load as a necessary condition for selective attention. Journal of Experimental Psychology: Human Perception and Performance, 21, 451-468.

Liu, T., Slotnick, S. D., Serences, J. T., \& Yantis, S. (2003). Cortical mechanisms of feature-based attentional control. Cerebral Cortex, 13, 1334-1343.

Luck, S. J., Chelazzi, L., Hillyard, S. A., \& Desimone, R. (1997). Neural mechanisms of spatial selective attention in areas V1, V2, and V4 of macaque visual cortex. Journal of Neurophysiology, 77, 24-42.

Martinez Trujillo, J. C., \& Treue, S. (2004). Feature-based attention increases the selectivity of population responses in primate visual cortex. Current Biology, 14, 744-751.

Maruff, P., Danckert, J., Camplin, G., \& Currie, J. (1999). Behavioral goals constrain the selection of visual information. Psychological Science, 10, 522-525.

Maunsell, J. H. R., \& Hochstein, S. (1991). Effects of behavioral state on the stimulus selectivity of neurons in area V4 of the macaque monkey. In B. Blum (Ed.), Channels in the visual nervous system: Neurophysiology, psychophysics and models (pp. 447-470). London: Freund Publishing House.

McCarthy, G., \& Donchin, E. (1981). A metric for thought: A comparison of P300 latency and reaction time. Science, 211, 77-80.

McCarthy, G., Luby, M., Gore, J., \& Goldman Rakic, P. (1997). Infrequent events transiently activate human prefrontal and parietal cortex as measured by functional MRI. Journal of Neurophysiology, 77, 1630-1634.

McCarthy, G., Wood, C. C., Williamson, P. D., \& Spencer, D. D. (1989). Task-dependent field potentials in human hippocampal formation. Journal of Neuroscience, 9 , 4253-4268. 
McClurkin, J. W., \& Optican, L. M. (1996). Primate striate and prestriate cortical neurons during discrimination. I Simultaneous temporal encoding of information about color and pattern. Journal of Neurophysiology, 75 , 481-495.

Milliken, B., Joordens, S., Merikle, P. M., \& Seiffert, A. E. (1998). Selective attention: A reevaluation of the implications of negative priming. Psychological Review, 105, 203-229.

Milner, B. (1963). Effects of different brain lesions on card-sorting. Archives of Neurology, 9, 90-100.

Miniussi, C., Wilding, E. L., Coull, J. T., \& Nobre, A. C. (1999). Orienting attention in time. Modulation of brain potentials. Brain, 122, 1507-1518.

Mishkin, M., \& Ungerleider, L. G. (1982). Contribution of striate inputs to the visuospatial functions of parieto-preoccipital cortex in monkeys. Behavioural Brain Research, 6, 57-77.

Moran, J., \& Desimone, R. (1985). Selective attention gates visual processing in the extrastriate cortex. Science, 229, $782-784$.

Morton, J. (1969). Interaction of information in word recognition. Psychological Review, 76, 165-178.

Motter, B. C. (1993). Focal attention produces spatially selective processing in visual cortical areas V1, V2, and $\mathrm{V} 4$ in the presence of competing stimuli. Journal of Neurophysiology, 70, 909-919.

Motter, B. C. (1994). Neural correlates of feature selective memory and pop-out in extrastriate area V4. Journal of Neuroscience, 14, 2190-2199.

Mueller, H. J., Heller, D., \& Ziegler, J. (1995). Visual search for singleton feature targets within and across feature dimensions. Perception and Psychophysics, 57, 1-17.

Neill, W. T. (1977). Inhibitory and facilitatory processes in selective attention. Journal of Experimental Psychology: Human Perception and Performance, 3, 444-450.

Neill, W. T., Valdes, L. A., Terry, K. M., \& Gorfein, D. S. (1992). Persistence of negative priming: II. Evidence for episodic trace retrieval. Journal of Experimental Psychology: Learning, Memory, and Cognition, 18, 993-1000.

Nobre, A. C. (2001). The attentive homunculus: Now you see it, now you don't. Neuroscience and Biobehavioral Reviews, 25, 477-496.

Nobre, A. C. (2004). Probing the flexibility of attentional orienting in the human brain. In M. Posner (Ed.), Cognitive neuroscience of attention (pp. 157-179). New York: Guilford Press.

Nobre, A. C., Sebestyen, G. N., \& Miniussi, C. (2000). The dynamics of shifting visuospatial attention revealed by event-related potentials. Neuropsychologia, 38, 964-974.

O'Craven, K. M., Downing, P. E., \& Kanwisher, N. (1999). fMRI evidence for objects as the units of attentional selection. Nature, 401, 584-587.

O'Craven, K. M., Rosen, B. R., Kwong, K. K., Treisman, A., \& Savoy, R. L. (1997). Voluntary attention modulates fMRI activity in human MT-MST. Neuron, 18, 591-598.

Oldfield, R. C. (1971). The assessment and analysis of handedness: The Edinburgh inventory. Neuropsychologia, 9, 97-113.

Park, J., \& Kanwisher, N. (1994). Negative priming for spatial locations: Identity mismatching, not distractor inhibition. Journal of Experimental Psychology: Human Perception and Performance, 20, 613-623.

Picton, T. W. (1992). The P300 wave of the human event-related potential. Journal of Clinical Neurophysiology, 9, 456-479.

Polich, J. (1998). P300 clinical utility and control of variability. Journal of Clinical Neurophysiology, 15, 14-33.
Pollmann, S., Weidner, R., Muller, H. J., \& von Cramon, D. Y. (2000). A fronto-posterior network involved in visual dimension changes. Journal of Cognitive Neuroscience, 12, 480-494.

Posner, M. I. (1980). Orienting of attention. Quarterly Journal of Experimental Psychology, 32, 3-25.

Remington, R. W., \& Folk, C. L. (2001). A dissociation between attention and selection. Psychological Science, $12,511-515$.

Reynolds, J. H., Chelazzi, L., \& Desimone, R. (1999). Competitive mechanisms subserve attention in macaque areas V2 and V4. Journal of Neuroscience, 19, 1736-1753.

Rodriguez, V., Valdes Sosa, M., \& Freiwald, W. (2002). Dividing attention between form and motion during transparent surface perception. Brain Research, Cognitive Brain Research, 13, 187-193.

Roelfsema, P. R., Lamme, V. A., \& Spekreijse, H. (1998). Object-based attention in the primary visual cortex of the macaque monkey. Nature, 395, 376-381.

Rogers, R. D., \& Monsell, S. (1995). Costs of a predictible switch between simple cognitive tasks. Journal of Experimental Psychology: General, 124, 207-231.

Rossi, A. F., \& Paradiso, M. A. (1995). Feature-specific effects of selective visual attention. Vision Research, 35, 621-634.

Rugg, M. D., \& Coles, M. G. H. (1995). Electrophysiology of mind: Event-related brain potentials and cognition. Oxford: Oxford University Press.

Rushworth, M. F., Nixon, P. D., Renowden, S., Wade, D. T., \& Passingham, R. E. (1997). The left parietal cortex and motor attention. Neuropsychologia, 35, 1261-1273.

Rushworth, M. F., Nobre, A. C., \& Passingham, R. E. (2005). Components of attentional set-switching. Experimental Psychology, 52, 83-98.

Rushworth, M. F., Passingham, R. E., \& Nobre, A. C. (2002). Components of switching intentional set. Journal of Cognitive Neuroscience, 14, 1139-1150.

Rushworth, M. F., Passingham, R. E., \& Nobre, A. C. (2005). Contrasting components of attentional and intentional set-switching. Experimental Psychology, 52, 83-98.

Saenz, M., Buracas, G. T., \& Boynton, G. M. (2002). Global effects of feature-based attention in human visual cortex. Nature Neuroscience, 5, 631-632.

Saenz, M., Buracas, G. T., \& Boynton, G. M. (2003). Global feature-based attention for motion and color. Vision Research, 43, 629-637.

Saron, C. D., Schroeder, C. E., Foxe, J. J., \& Vaughan, H. G., Jr. (2001). Visual activation of frontal cortex: Segregation from occipital activity. Brain Research, Cognitive Brain Research, 12, 75-88.

Schoenfeld, M. A., Heinze, H. J., \& Woldorff, M. G. (2002). Unmasking motion-processing activity in human brain area $\mathrm{V} 5 / \mathrm{MT}+$ mediated by pathways that bypass primary visual cortex. Neuroimage, 17, 769-779.

Serences, J. T., Schwarzbach, J., Courtney, S. M., Golay, X., \& Yantis, S. (2004). Control of object-based attention in human cortex. Cerebral Cortex, 14, 1346-1357.

Smith, M. E., Halgren, E., Sokolik, M., Baudena, P., Musolino, A., Liegeois Chauvel, C., \& Chauvel, P. (1990). The intracranial topography of the $\mathrm{P} 3$ event-related potential elicited during auditory oddball. Electroencephalography and Clinical Neurophysiology, 76, 235-248.

Stroop, J. R. (1935). Studies of interference in serial verbal reactions. Journal of Experimental Psychology, 18, 643-662.

Tipper, S. P. (1985). The negative priming effect: Inhibitory priming by ignored objects. Quarterly Journal of Experimental Psychology, A, 37, 571-590. 
Tipper, S. P. (2001). Does negative priming reflect inhibitory mechanisms? A review and integration of conflicting views. Quarterly Journal of Experimental Psychology, A, 54, 321-343.

Tipper, S. P., \& Driver, J. (1988). Negative priming between pictures and words in a selective attention task: Evidence for semantic processing of ignored stimuli. Memory $\varepsilon$ Cognition, 16, 64-70.

Treisman, A., \& Fearnley, S. (1969). The Stroop test: Selective attention to colours and words. Nature, 222, 437-439.

Treisman, A. M., \& Gelade, G. (1980). A feature-integration theory of attention. Cognitive Psychology, 12, 97-136.

Treue, S., \& Martinez Trujillo, J. C. (1999). Feature-based attention influences motion processing gain in macaque visual cortex. Nature, 399, 575-579.

Treue, S., \& Maunsell, J. H. (1996). Attentional modulation of visual motion processing in cortical areas MT and MST. Nature, 382, 539-541.
Valdes Sosa, M., Bobes, M. A., Rodriguez, V., \& Pinilla, T (1998). Switching attention without shifting the spotlight object-based attentional modulation of brain potentials. Journal of Cognitive Neuroscience, 10, 137-151.

Valdes Sosa, M., Cobo, A., \& Pinilla, T. (1998). Transparent motion and object-based attention. Cognition, 66, B13-B23.

Verleger, R. (1997). On the utility of P3 latency as an index of mental chronometry. Psychophysiology, 34, 131-156.

Wojciulik, E., \& Kanwisher, N. (1999). The generality of parietal involvement in visual attention. Neuron, 23, 747-764.

Yamaguchi, S., \& Knight, R. T. (1991). Anterior and posterior association cortex contributions to the somatosensory P300. Journal of Neuroscience, 11, 2039-2054.

Yantis, S., \& Serences, J. T. (2003). Cortical mechanisms of space-based and object-based attentional control. Current Opinion in Neurobiology, 13, 187-193.

Zeki, S. (1993). The visual association cortex. Current Opinion in Neurobiology, 3, 155-159. 